OPEN ACCESS

Edited by:

Guangchun Bai,

Albany Medical College, USA

Reviewed by: Jan-Willem Veening, University of Groningen, Netherlands William R. McCleary,

Brigham Young University, USA

${ }^{*}$ Correspondence:

Malcolm E. Winkler winklerm@indiana.edu

Received: 22 April 2016 Accepted: 27 May 2016 Published: 20 June 2016

Citation:

Zheng JJ, Sinha D, Wayne KJ and Winkler ME (2016) Physiological Roles of the Dual Phosphate Transporter Systems in Low and High Phosphate

Conditions and in Capsule Maintenance of Streptococcus pneumoniae $D 39$

Front. Cell. Infect. Microbiol. 6:63. doi: 10.3389/fcimb.2016.00063

\section{Physiological Roles of the Dual Phosphate Transporter Systems in Low and High Phosphate Conditions and in Capsule Maintenance of Streptococcus pneumoniae D39}

\author{
Jiaqi J. Zheng, Dhriti Sinha, Kyle J. Wayne and Malcolm E. Winkler* \\ Department of Biology, Indiana University Bloomington, Bloomington, IN, USA
}

Unlike most bacteria, Streptococcus pneumoniae (pneumococcus) has two evolutionarily distinct ABC transporters (Pst1 and Pst2) for inorganic phosphate $\left(\mathrm{P}_{\mathrm{i}}\right)$ uptake. The genes encoding a two-component regulator (PnpRS) are located immediately upstream of the pst1 operon. Both the pst1 and pst2 operons encode putative PhoU-family regulators (PhoU1 and PhoU2) at their ends. This study addresses why $S$. pneumoniae contains dual $\mathrm{P}_{\mathrm{i}}$ uptake systems and the regulation and contribution of the Pst1 and Pst2 systems in conditions of high $(\mathrm{mM}) \mathrm{P}_{\mathrm{i}}$ amount and low $(\mu \mathrm{M}) \mathrm{P}_{\mathrm{i}}$ amount. We show that in unencapsulated mutants, both pst1 and pst2 can be deleted, and $\mathrm{P}_{\mathrm{i}}$ is taken up by a third $\mathrm{Na}^{+} / \mathrm{P}_{\mathrm{i}}$ co-transporter, designated as NptA. In contrast, either pst1 or pst2 is unexpectedly required for the growth of capsule producing strains. We used a combination of mutational analysis, transcript level determinations by qRT-PCR and RNA-Seq, assays for cellular PnpR P amounts by SDS-PAGE, and pulse- $P_{i}$ uptake experiments to study the regulation of $P_{i}$ uptake. In high $P_{i}$ medium, PhoU2 serves as the master negative regulator of Pst2 transporter function and PnpR $\sim P$ levels (post-transcriptionally). $\Delta$ phoU2 mutants have high PnpR P levels and induction of the pst1 operon, poor growth, and sensitivity to antibiotics, possibly due to high $\mathrm{P}_{\mathrm{i}}$ accumulation. In low $\mathrm{P}_{\mathrm{i}}$ medium, Pst2 is still active, but PnpR P amount and pst1 operon levels increase. Together, these results support a model in which pneumococcus maintains high $\mathrm{P}_{\mathrm{i}}$ transport in high and low $\mathrm{P}_{\mathrm{i}}$ conditions that is required for optimal capsule biosynthesis. Keywords: PhoU, PnpRS two-component system (TCS), PnpR P phosphorylation, Pst1 and Pst2 $P_{\mathrm{i}}$ ABC
transporters, NptA Na $/ \mathrm{P}_{\mathrm{i}}$ co-transporter

\section{INTRODUCTION}

Phosphorus is an essential element in all cells because of its structural and metabolic roles in nearly all biological processes, including the composition of nucleic acids, phospholipids, and energy intermediates. A preferred source of phosphorous for bacterial cells is environmental inorganic orthophosphate $\left(\mathrm{PO}_{4}^{-} ; \mathrm{P}_{\mathrm{i}}\right)$. The mechanism of extracellular $\mathrm{P}_{\mathrm{i}}$ uptake has been studied intensively 
in Escherichia coli and Bacillus subtilis as model organisms (Hulett, 1993; Takemaru et al., 1996; Wanner, 1996; Qi et al., 1997; Lamarche et al., 2008; Hsieh and Wanner, 2010; Botella et al., 2011, 2014), and recently in other bacterial species (Braibant et al., 1996; Gonin et al., 2000; Zaborina et al., 2008; Rifat et al., 2009; Shi and Zhang, 2010; Burut-Archanai et al., 2011; Cheng et al., 2012; Wang et al., 2013; de Almeida et al., 2015; Lubin et al., 2016). Generally, bacterial highaffinity $\mathrm{P}_{\mathrm{i}}$ uptake systems consist of an ATP-binding cassette $(\mathrm{ABC})$ transporter, designated as Pst (for phosphate-specific transporter), which contains at least four component subunits: an extracellular $\mathrm{P}_{\mathrm{i}}$ binding protein (PstS), two transmembrane channel proteins (PstCA), and a cytoplasmic ATPase (PstB) (see Figure 1; Hsieh and Wanner, 2010). The expression of most bacterial Pst transporters is regulated at the transcriptional level by a two-component regulatory system (TCS), which has different designations in different bacteria (Hulett, 1993; Novak et al., 1999; Throup et al., 2000; Howell et al., 2006; Glover et al., 2007). Many bacteria also regulate $P_{i}$ uptake by an ancillary negative regulatory protein, designated PhoU (Steed and Wanner, 1993; Botella et al., 2011, 2014; de Almeida et al., 2015; Lubin et al., 2016).

In E. coli and related enterobacteria, the histidine kinase (HK) and response regulator (RR) that mediate $\mathrm{P}_{\mathrm{i}}$ transport are designated as PhoR and PhoB, respectively, and the regulation of $\mathrm{P}_{\mathrm{i}}$ uptake involves a PhoU regulator (Hsieh and Wanner, 2010; Gardner et al., 2014, 2015). Briefly, when $\left[\mathrm{P}_{\mathrm{i}}\right]>4.0 \mu \mathrm{M}$, the expression of the phoB-phoR regulator and pst transporter operons is inhibited by PhoU by a mechanism described below (Hsieh and Wanner, 2010). When the $\left[\mathrm{P}_{\mathrm{i}}\right]$ is depleted to $<4.0 \mu \mathrm{M}$, PhoU releases inhibition of the PhoR HK and the PstB subunit of the transporter, allowing autophosphorylation of the PhoR HK, phosphoryl transfer to the PhoB RR, and activation of transcription by $\mathrm{PhoB} \sim \mathrm{P}$ of operons in the phosphate (pho) regulon, including the pst transporter, the phoB-phoR regulator, and other operons involved in the uptake and assimilation of phosphorous-containing compounds (Wanner, 1996; Hsieh and Wanner, 2010). PhoB $\sim \mathrm{P}$ activates transcription by binding to the Pho box sequence upstream from the promoters of the regulon operons, including phoB-phoR, which provides autoregulation of the TCS proteins (Wanner, 1996; Martin, 2004; Lubin et al., 2016). Usually, the sequence of the consensus Pho box is different between Gram-negative (e.g., E. coli) and Grampositive (e.g., B. subtilis) bacteria (Martin, 2004). Since the Pst transporter is not activated in E. coli at high $\mathrm{P}_{\mathrm{i}}$ concentrations, this system is considered as a high-affinity transporter that works predominantly at low $\mathrm{P}_{\mathrm{i}}$ concentrations (Wanner, 1996). $\mathrm{PhoB} / \mathrm{R}$, the Pst transporter, and members of the Pho regulon are important for virulence in many pathogenic Gram-negative bacteria, including E. coli, Vibrio cholerae, Proteus mirabilis, and Pseudomonas aeruginosa (Jacobsen et al., 2008; Lamarche et al., 2008; Zaborina et al., 2008; Pratt et al., 2010; Chekabab et al., 2014a,b). In P. aeruginosa, the PstS $P_{\mathrm{i}}$ binding protein also plays roles in adhesion and a $\mathrm{P}_{\mathrm{i}}$-independent role in biofilm formation (Zaborina et al., 2008; Neznansky et al., 2014; Shah et al., 2014).

$\mathrm{PhoU}$ is a negative regulator of Pho regulon expression in E. coli and many other bacteria (Muda et al., 1992; Wanner,
1996; Hsieh and Wanner, 2010; Gardner et al., 2014; de Almeida et al., 2015). Although, PhoU is an important regulator in many bacteria, it is notably absent from certain Gram-positive bacteria, including B. subtilis (Qi et al., 1997; Moreno-Letelier et al., 2011). phoU deletion in E. coli, P. aeruginosa, and Mycobacterium marinum leads to growth defects (Steed and Wanner, 1993; Wanner, 1996; Rice et al., 2009; Wang et al., 2013; de Almeida et al., 2015). In E. coli, this growth defect is reversed by deletion of the pst transporter operon or the phoBR TCS operon (Steed and Wanner, 1993; Wanner, 1996). These observations suggest that the growth defect of phoU mutants is caused by unregulated function of the Pst transport system, leading to excess $P_{i}$ accumulation (Wanner, 1996; Rice et al., 2009). $\Delta p h o U$ mutants also accumulate increased amounts of poly-orthophosphate (poly- $\mathrm{P}_{\mathrm{i}}$ ) in E. coli, M. marinum, $P$. aeruginosa, and Caulobacter crescentus (Morohoshi et al., 2002; Hirota et al., 2013; Wang et al., 2013; de Almeida et al., 2015; Lubin et al., 2016). Poly- $\mathrm{P}_{\mathrm{i}}$ also accumulates in E. coli K-12 cells in stationary phase in high $P_{i}$ medium, and this accumulation is correlated with inhibition of biofilm formation mediated by $\mathrm{PhoB} \sim \mathrm{P}$ RR phosphorylation with acetyl-phosphate acting as donor (Grillo-Puertas et al., 2016). The rate of $P_{i}$ uptake was reported to increase in an E. coli $\Delta p h o U$ in one study (Rice et al., 2009), but not in another (Steed and Wanner, 1993). Besides defective growth, $\Delta$ phoU mutants exhibit higher sensitivity to a diverse range of antibiotics in E. coli, Mycobacterium tuberculosis, M. marinum, and P. aeruginosa (Li and Zhang, 2007; Shi and Zhang, 2010; Wang et al., 2013; de Almeida et al., 2015) and a defect in mutagenic DNA break repair in E. coli (Gibson et al., 2015).

Recent papers demonstrate that $E$. coli PhoU interacts with the PAS domain of the PhoR HK and with the PstB ATPase protein, in support of the dual inhibition of Pho regulon transcription and Pst mediated transport in E. coli (Gardner et al., 2014, 2015). Three crystal structures of PhoU-like proteins have been reported from Aquifex aeolicus, Thermotoga maritima, and $P$. aeruginosa (Liu et al., 2005; Oganesyan et al., 2005; Lee et al., 2014), showing that PhoU consists of two symmetric, threealpha-helix bundles. However, these PhoU proteins showed several quaternary structures in crystals, including monomer, dimer, or hexamer packing (Liu et al., 2005; Oganesyan et al., 2005; Lee et al., 2014). Gel filtration shows that purified $E$. coli PhoU forms a dimer in solution (Gardner et al., 2014). In addition, divalent cation binding of magnesium and manganese is required for E. coli PhoU binding to the cytoplasmic side of the inner membrane and may play a role in formation of a ternary regulatory complex containing PhoU, PhoR, and PstB (Gardner et al., 2014). On the other hand, a recent study suggests that a different paradigm operates in C. crescentus, where PhoU does not modulate PhoR HK activity directly (Lubin et al., 2016). Instead, PhoU may negatively regulate the activity of the Pst transporter in response to $P_{i}$ availability in C. crescentus (Lubin et al., 2016).

Besides Pst $A B C$ transporters, $P_{i}$ is taken up by symporter secondary transport systems. In $E$. coli, two additional $\mathrm{P}_{\mathrm{i}}$ transporters, PitA and $\mathrm{PitB}$, have been identified that are symporters of divalent cations, such as $\mathrm{Mg}^{2+}$ and $\mathrm{Ca}^{2+}$ (van Veen 


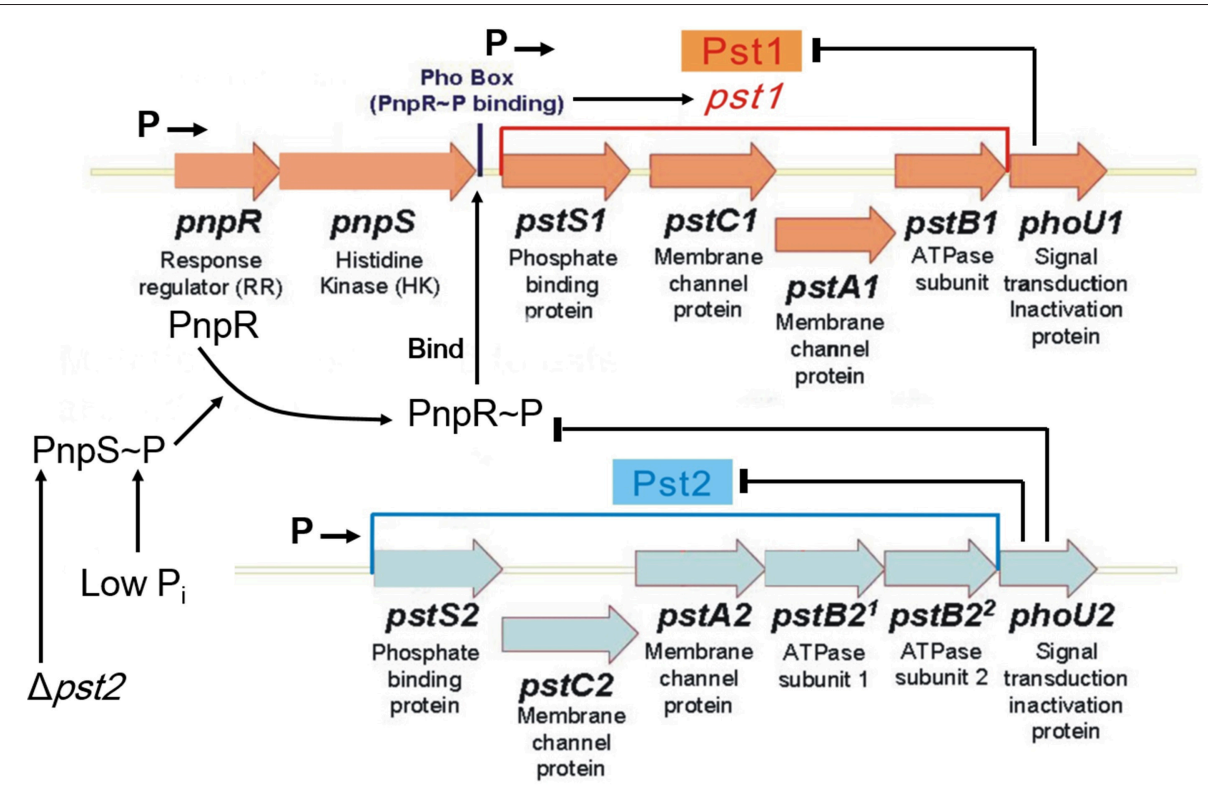

FIGURE 1 | Model for regulation of the dual Pst1 and Pst2 ABC $P_{i}$ transporters in Streptococcus pneumoniae D39. Genomic sequencing and transcriptome analyses show that pnpRS, pst1-phoU1, and pst2-phoU2 are organized into three distinct operons that are transcribed from separate promoters, indicated by Ps followed by arrows (see text). The Pst2 ABC $P_{j}$ transporter is constitutively expressed in both high and low $\mathrm{P}_{\mathrm{i}}$ conditions. PhoU2 inhibits phosphorylation of the PnpR response regulator (RR) and negatively regulates the transport activity of Pst2. In the absence of PhoU2, PnpR is phosphorylated by the PnpS histidine kinase (HK). PnpR P binds to the Pho box upstream of the pst1-phoU1 operon and activates transcription and expression of the genes encoding the Pst1 transporter and PhoU1 regulator; however, PnpR P does not autoregulate its own (pnpRS) transcription. In contrast to PhoU2, PhoU1 negatively regulates the transport activity of Pst1, but does not regulate phosphorylation of PnpR. In the absence of the Pst2 transporter or in low Pi conditions, the PnpRS two component system (TCS) activates the expression of the genes encoding the Pst1 transporter and PhoU1 regulator. Either the Pst1 or Pst2 $\mathrm{P}_{\mathrm{j}}$ transporter is required in encapsulated cells. Therefore, the regulated Pst1 and constitutive Pst2 $\mathrm{P}_{\mathrm{i}}$ transport systems may act as a redundant failsafe to ensure that capsule biosynthesis is maintained during variations in $\mathrm{P}_{\mathrm{i}}$ conditions. See the text for additional details.

et al., 1994; Wanner, 1996; Harris et al., 2001; Jackson et al., 2008). PitA and PitB have been considered as low-affinity $\mathrm{P}_{\mathrm{i}}$ transporters that predominantly function in high $\mathrm{P}_{\mathrm{i}}$ environments (Wanner, 1996; Hsieh and Wanner, 2010). Moreover, expression of pitA is induced by $\mathrm{Zn}^{2+}$ addition (Jackson et al., 2008), suggesting that PitA may act primarily as a metal ion transporter instead of a $\mathrm{P}_{\mathrm{i}}$ transporter (Beard et al., 2000).

Unlike E. coli, B. subtilis, or C. crescentus, which contain only one Pst transporter, Streptococcus pneumoniae (pneumococcus) encodes two evolutionarily distinct $\mathrm{P}_{\mathrm{i}} \mathrm{ABC}$ pump transporters, Pst1 and Pst2 (Figure 1; Lanie et al., 2007; Moreno-Letelier et al., 2011). The multigene pst 1 and pst 2 operons are located at different locations in the pneumococcus chromosome (Lanie et al., 2007). Only one $p h o B R$-like TCS, $p n p R S$, encoding the PnpR RR and the PnpS HK, is encoded upstream of the pst1 operon, and both the pst 1 and pst 2 transporter operons encode separate PhoU-family regulators, designated PhoU1 and PhoU2 (Figure 1). The PnpRS TCS, Pst1 transporter, and PhoU1 were initially studied in unencapsulated $S$. pneumoniae laboratory strain R6x (Novak et al., 1999), before the discovery of the second Pst2 transporter and PhoU2 regulator. This work indicated that $p n p R S$ operon expression was not regulated by $\mathrm{P}_{\mathrm{i}}$ amount, and that mutants deficient in the PstB1 ATPase subunit seemed to show decreased $\mathrm{P}_{\mathrm{i}}$ uptake in certain growth media (Novak et al., 1999). Subsequent work suggests that upregulation of pst1 operon expression is correlated with increased $\beta$-lactam antibiotic resistance in low-affinity $p b p 2 x$ mutants and some clinical isolates of S. pneumoniae (Soualhine et al., 2005; Engel et al., 2014).

S. pneumoniae is a common commensal bacterium that primarily colonizes the human nasopharynx (Donkor, 2013; Chao et al., 2014; Hakansson et al., 2015; Short and Diavatopoulos, 2015), but can become an opportunistic pathogen, causing several serious respiratory and invasive diseases (Henriques-Normark and Tuomanen, 2013; Vernatter and Pirofski, 2013; Ferreira and Gordon, 2015; Gratz et al., 2015; Oliver and Swords, 2015). Therefore, the Pst1 and Pst2 transporters must mediate $\mathrm{P}_{\mathrm{i}}$ acquisition from several niches with vastly different $\mathrm{P}_{\mathrm{i}}$ concentrations in human hosts (Orihuela et al., 2001; Wilson, 2005, 2008). Signature-tagged mutagenesis (STM) screens and a study of the role of the PnpR RR (also called RR04) indicated that the $p n p R S$, pst1, and pst 2 operons are all required for full pneumococcal virulence (Polissi et al., 1998; Throup et al., 2000; Hava and Camilli, 2002; McCluskey et al., 2004; Paterson et al., 2006; Trihn et al., 2013). Consistent with these earlier studies, a recent Tn-Seq study showed that PhoU1 is important for nasopharynx colonization, whereas PhoU2 is important for lung infection (van Opijnen and Camilli, 2012).

In this report, we studied the transcriptional and functional regulation of the pneumococcal Pst1 and Pst2 $\mathrm{P}_{\mathrm{i}}$ transporters 
under growth conditions containing high $(\approx 18 \mathrm{mM})$ or low $(\approx 100 \mu \mathrm{M})$ concentrations of $\mathrm{P}_{\mathrm{i}}$. Our results show that pst 2 operon transcription is constitutive, but Pst 2 transporter activity is negatively regulated by PhoU2. In addition, PhoU2 negatively regulates PnpR RR phosphorylation and transcription of the pst1 operon at high concentrations of $\mathrm{P}_{\mathrm{i}}$. Therefore, PhoU2 resembles $E$. coli $\mathrm{PhoU}$ in that it functions in regulating the level of RR phosphorylation, besides modulating Pst2 transporter activity. In contrast, PhoU1 resembles C. crescentus PhoU in that it only regulates Pst1 transporter activity and does not modulate PnpRS TCS function. Our results also indicate that encapsulated $S$. pneumoniae requires the function of Pstl or Pst2 for growth, whereas a symporter, named NptA, can provide sufficient $\mathrm{P}_{\mathrm{i}}$ to allow the growth of unencapsulated mutants in high $\mathrm{P}_{\mathrm{i}}$ conditions.

\section{MATERIALS AND METHODS}

\section{Bacterial Strains and Growth Conditions}

Strains used in this study are listed in Table S1. Encapsulated strains were derived from parent strain IU1781 (D39 cps ${ }^{+}$ rpsL1), and unencapsulated strains were derived from parent strains IU1945 (D39 $\Delta c p s$ ), IU1824 (D39 $\Delta c p s$ rpsL1), and IU3309 (D39 $\Delta$ cps2E rpsL1), which are derivatives of serotype 2 S. pneumoniae strain D39 IU1690 (Lanie et al., 2007). Strains containing antibiotic markers were constructed by transformation of competent pneumococcal cells with linear DNA amplicons synthesized by overlapping fusion PCR (Ramos-Montanez et al., 2008; Tsui et al., 2010). Strains containing markerless alleles in native chromosomal loci were constructed using allele replacement via the $\mathrm{Pc}-\left[k a n-r p s L^{+}\right]$ (Janus cassette; Sung et al., 2001). Primers used to synthesize different amplicons are listed in Table S2. All constructs were confirmed by DNA sequencing of chromosomal regions corresponding to the amplicon region used for transformation. Bacteria were grown on plates containing trypticase soy agar II (modified; Becton-Dickinson) and 5\% (vol/vol) defibrinated sheep blood (TSAII-BA). Plates were incubated at $37^{\circ} \mathrm{C}$ in an atmosphere of $5 \% \mathrm{CO}_{2}$. For selections of transformants, TSAII-BA plates contained $250 \mu \mathrm{g} / \mathrm{mL}$ kanamycin, $0.3 \mu \mathrm{g} / \mathrm{mL}$ erythromycin, or $250 \mu \mathrm{g} / \mathrm{mL}$ streptomycin. Strains were cultured statically in Becton-Dickinson brain heart infusion (BHI) broth at $37^{\circ} \mathrm{C}$ in an atmosphere of $5 \% \mathrm{CO}_{2}$, and growth was monitored by $\mathrm{OD}_{620}$ as described before (Tsui et al., 2016). Transformants were single-colony-isolated on TSAII-BA plates containing antibiotics twice before growth in antibioticcontaining BHI broth for storage (Tsui et al., 2016). All mutant constructs were confirmed by DNA sequencing of chromosomal regions corresponding to the amplicon region used for transformation.

Static growth in BHI broth, which contains $\approx 18 \mathrm{mM} \mathrm{P}_{\mathrm{i}}$, was used as a high $\mathrm{P}_{\mathrm{i}}$ condition. For growth curves, strains were inoculated into $3 \mathrm{~mL}$ of $\mathrm{BHI}$ broth, serially diluted, and grown overnight. The next day, cultures with $\mathrm{OD}_{620}=0.1-$ 0.3 were diluted into $5 \mathrm{~mL}$ of fresh $\mathrm{BHI}$ broth to $\mathrm{OD}_{620} \approx 0.002$, and growth was monitored hourly. $\mathrm{C}+\mathrm{Y}$ medium (Lacks and Hotchkiss, 1960) was used for studies of moderately low $\mathrm{P}_{\mathrm{i}}$ condition. We determined that $\mathrm{C}+\mathrm{Y}$ broth (no added $\mathrm{P}_{\mathrm{i}}$ ) already contains $\approx 1.5 \mathrm{mM} \mathrm{P}_{\mathrm{i}}$ (see Results). A modified chemically defined medium (mCDM) (Carvalho et al., 2013) was used for moderate and low $\mathrm{P}_{\mathrm{i}}$ conditions. To optimize growth, the concentrations of choline- $\mathrm{HCl}$ and all amino acids amounts were increased by 1000 -fold and tyrosine was added to $100 \mathrm{mg} / \mathrm{L}$ compared to the CDM recipe in Carvalho et al. (2013). In addition, $40 \mathrm{mM}$ MOPS buffer was added to $\mathrm{mCDM}$, which was adjusted to a final $\mathrm{pH}=7.4$ with $10 \mathrm{M} \mathrm{NaOH}$. mCDM contains $36.4 \mathrm{mM} \mathrm{P} \mathrm{P}_{\mathrm{i}}\left(\right.$ Carvalho et al., 2013). $\mathrm{mCDM}$ with no $\mathrm{P}_{\mathrm{i}}$ was made by omitting $\mathrm{KH}_{2} \mathrm{PO}_{4}$ and $\mathrm{K}_{2} \mathrm{HPO}_{4}$ and adding $\mathrm{KCl}$ to $50.8 \mathrm{mM}$. mCDM media with $2 \mathrm{mM}$ or $1 \mathrm{mM} \mathrm{P}_{\mathrm{i}}$ was made by mixing $\mathrm{mCDM}$ and $\mathrm{mCDM}$ lacking $\mathrm{P}_{\mathrm{i}}$ in a ratio of $2-34.4$ or $1-35.4$, respectively. $\mathrm{mCDM}$ with $1 \mathrm{mM} \mathrm{P}_{\mathrm{i}}$ was diluted 10 or 100 -fold with mCDM lacking $\mathrm{P}_{\mathrm{i}}$ make $\mathrm{mCDM}$ with $100 \mu \mathrm{M}$ and $10 \mu \mathrm{M} \mathrm{P}_{\mathrm{i}}$, respectively. For growth in $\mathrm{mCDM}, 3 \mathrm{~mL}$ overnight cultures were grown as described above, and the next day, cultures with $\mathrm{OD}_{620}$ $=0.1-0.3$ were centrifuged $\left(5125 \times \mathrm{g}, 5 \mathrm{~min}, 25^{\circ} \mathrm{C}\right)$, washed with $3 \mathrm{~mL}$ mCDM lacking $\mathrm{P}_{\mathrm{i}}$ twice, and resuspended in $3 \mathrm{~mL} \mathrm{mCDM}$ lacking $\mathrm{P}_{\mathrm{i}}$. Cells were then diluted in $5 \mathrm{~mL}$ of $\mathrm{mCDM}$ with 2 , $1 \mathrm{mM}, 100,10 \mu \mathrm{M}$, or no $\mathrm{P}_{\mathrm{i}}$ to $\mathrm{OD} \approx 0.005$ and growth of static cultures in an atmosphere of $5 \% \mathrm{CO}_{2}$ was monitored hourly at $\mathrm{OD}_{620}$.

\section{Antibiotic Disk Diffusion Assays}

Overnight cultures were diluted and grown in $5 \mathrm{~mL}$ of $\mathrm{BHI}$ to $\mathrm{OD}_{620} \approx 0.1$. $100 \mu \mathrm{L}$ of cultures were mixed with $3 \mathrm{~mL}$ of nutrient-broth soft agar $[0.8 \%(\mathrm{w} / \mathrm{v})$ nutrient broth and $0.7 \%$ (w/v) Bacto Agar (Difco)] and poured onto TSAII-BA plates. After $15 \mathrm{~min}$, antibiotics disks were placed at the middle of plates, which were incubated at $37^{\circ} \mathrm{C}$ in an atmosphere of $5 \% \mathrm{CO}_{2}$ overnight for $16 \mathrm{~h}$. Diameters of zones of growth inhibition were measured with a ruler, and $P$-values were calculated by unpaired $t$-test in GraphPad Prism. Antibiotic disks were from Becton, Dickinson Co.: cefotaxime $(30 \mu \mathrm{g})$; cefazolin $(30 \mu \mathrm{g})$; cefamandole $(30 \mu \mathrm{g})$; ceftazidime $(30 \mu \mathrm{g})$; amdinocillin $(10 \mu \mathrm{g})$; vancomycin $(30 \mu \mathrm{g})$; gentamicin $(120 \mu \mathrm{g})$; and tetracycline $(30 \mu \mathrm{g})$.

\section{RNA Preparation, qRT-PCR, and RNA-Seq Analyses}

To study high $\mathrm{P}_{\mathrm{i}}$ conditions, overnight cultures were diluted and grown in $5 \mathrm{~mL}$ of $\mathrm{BHI}$ to $\mathrm{OD} \approx 0.15$. Cells were collected by centrifuging at $16,000 \times \mathrm{g}$ for $5 \mathrm{~min}$ at $4^{\circ} \mathrm{C} .1 \mathrm{~mL}$ of RNApro solution (MP Biomedicals) was added to resuspend cell pellets. The suspension was transferred to a Lysing Matrix B tube (MP Biomedicals), which was shaken $3 \mathrm{X}$ in FastPrep homogenizer (6.0 $\mathrm{M} / \mathrm{s}$ for $40 \mathrm{~s}$ each). Cell debris and lysing matrix were removed by centrifugation at $16,000 \times g$ for $5 \mathrm{~min}$ at $4^{\circ} \mathrm{C}$. $700 \mu \mathrm{L}$ of supernates was transferred to a new microcentrifuge tube and incubated at room temperature for $5 \mathrm{~min}$. $300 \mu \mathrm{L}$ of chloroform was then added followed by incubation at room temperature for $5 \mathrm{~min}$. Mixtures were centrifuged at $16,000 \times g$ for $5 \mathrm{~min}$ at $4^{\circ} \mathrm{C} .280 \mu \mathrm{L}$ of the upper, aqueous phase was collected and mixed with $140 \mu \mathrm{L}$ of $100 \%$ Ethanol in a new microcentrifuge tube for RNA precipitation. RNA purification was done using miRNeasy minikit (Qiagen), including on-column treatment 
with DNase I (Qiagen), following the manufacturer's instructions. $5 \mu \mathrm{g}$ of purified RNA was treated by DNase from a DNAfree DNA removal kit (Ambion). 125 ng of treated RNA was used to synthesize cDNA by a qScript Felex cDNA synthesis kit (Quanta Biosciences). Synthesized cDNA was diluted 1:6 in water and then serially diluted 1:5 in water three more times. qRT-PCR reactions contained $10 \mu \mathrm{L}$ of $2 \times$ Brilliant III UltraFast SYBR Green QPCR Master Mix (Agilent), $2 \mu \mathrm{L}$ of each $2 \mu \mathrm{M}$ primers (Table S3), $0.3 \mu \mathrm{L}$ of a 1:500 dilution of ROX reference dye, and $6 \mu \mathrm{L}$ of diluted cDNA. Samples were run in an MX3000P thermocycler (Stratagene) with Program MxPro v. 3.0. Transcript amounts were normalized to gyrA mRNA amount and compared with transcript amounts of the wild-type parent strain by unpaired $t$-test in GraphPad Prism (Kazmierczak et al., 2009).

To study low $\mathrm{P}_{\mathrm{i}}$ conditions, bacteria from overnight $\mathrm{BHI}$ broth cultures were washed, diluted, and grown in $5 \mathrm{~mL}$ of $\mathrm{mCDM}$ medium containing $36.4 \mathrm{mM} \mathrm{P}_{\mathrm{i}}$ to $\mathrm{OD}_{620} \approx 0.15$. Cells were collected by centrifugation, washed twice with $5 \mathrm{~mL} \mathrm{mCDM}$ lacking $\mathrm{P}_{\mathrm{i}}$, and resuspended in $\mathrm{mCDM}$ containing $36.4 \mathrm{mM} \mathrm{P} \mathrm{P}_{\mathrm{i}}$ or $10 \mu \mathrm{M} \mathrm{P}_{\mathrm{i}}$. Cultures were incubated at $37^{\circ} \mathrm{C}$ in an atmosphere of $5 \% \mathrm{CO}_{2}$ for $30 \mathrm{~min}$. Lysis, RNA extraction, purification, and qRTPCR reactions were performed as described above, except that $16 \mathrm{~S}$ rRNA was used to normalize transcript amounts, because gyrA was down-regulated under low $\mathrm{P}_{\mathrm{i}}$ condition. All transcript amounts were compared with the wild-type parent strain grown in $\mathrm{mCDM}$ containing $36.4 \mathrm{mM}$.

RNA samples for RNA-Seq analyses were prepared from $30 \mathrm{~mL}$ cultures as described previously (Hoover et al., 2015) cDNA library construction, single-end, $100 \mathrm{bp}$-sequencing on a HiSeq 2000 sequencer (Illumina), and bioinformatic analyses were performed as described in Hoover et al. (2015). Falsediscovery rates (FDR) were calculated using Benjamini and Hochberg's algorithm (Benjamini and Hochberg, 1995) and a gene or region was defined as differentially expressed if it had an up- or down-fold change of 1.8 with a FDR $<0.05$. RNA-Seq data were deposited in the NCBI GEO database under accession number GSE80637.

\section{Phos-Tag SDS-PAGE and Western Blot}

Phos-tag SDS-PAGE and standard Western blotting were carried out as described previously (Wayne et al., 2010, 2012; Tsui et al., 2014). To study high $\mathrm{P}_{\mathrm{i}}$ conditions, overnight $\mathrm{BHI}$ broth cultures were diluted and grown up to $\mathrm{OD}_{620} \approx 0.2$ in $30 \mathrm{~mL}$ of BHI. Cells expressing PnpR-L-FLAG ${ }^{3}$ were lysed using a FastPrep homogenizer, and cell lysates were resolved by Phos-tag SDS-PAGE at $4^{\circ} \mathrm{C}$ (Wayne et al., 2012). Cells expressing PstS2HA were lysed by the same method, but resolved by standard SDS-PAGE (Tsui et al., 2014). PnpR-L-FLAG ${ }^{3}$ and PstS2-HA were detected by Western blotting as described previously (Tsui et al., 2014) using anti-FLAG or anti-HA antibody as primary antibody. Chemiluminescent signal in protein bands was quantitated by using an IVIS imaging system as described in Wayne et al. (2010).

To study low $\mathrm{P}_{\mathrm{i}}$ conditions, strains were grown in $30 \mathrm{~mL}$ of $\mathrm{mCDM}$ to $\mathrm{OD}_{620} \approx 0.2$ as described above. Cells were collected by centrifugation and washed twice with $30 \mathrm{~mL}$ of $\mathrm{mCDM}$ lacking
$\mathrm{P}_{\mathrm{i}}$. Cell pellets were resuspended in $30 \mathrm{~mL}$ of $\mathrm{mCDM}$ containing $36.4 \mathrm{mM} \mathrm{P}_{\mathrm{i}}$ or lacking $\mathrm{P}_{\mathrm{i}}$ and incubated statically at $37^{\circ} \mathrm{C}$ in an atmosphere of $5 \% \mathrm{CO}_{2}$ for $40 \mathrm{~min}$. Proteins samples were extracted and Phos-tag SDS-PAGE was performed as described above.

\section{Qualitative Quellung Assay for Capsule}

Overnight cultures were diluted and grown in $5 \mathrm{~mL}$ of $\mathrm{BHI}$ to $\mathrm{OD} \approx 0.15 .1 \mu \mathrm{L}$ of culture was mixed with $1 \mu \mathrm{L}$ of Type 2 pneumococcal antiserum (Statens Serum Institut) on a glass slide. A cover slip was placed on top of the mixture, which was viewed immediately with a $100 \mathrm{X}$ objective by a phase-contrast microscope. Cells surrounded by capsule appear enlarged or swollen.

\section{$P_{\mathbf{i}}$ Concentration Determination}

The $\mathrm{P}_{\mathrm{i}}$ amount in $\mathrm{C}+\mathrm{Y}$ broth was determined by the colorimetric method described in Katewa and Katyare (2003). Briefly, standards were prepared by dilution of a $\mathrm{KH}_{2} \mathrm{PO}_{4}$ stock to give final $\mathrm{P}_{\mathrm{i}}$ concentrations of $2.5,5.0,10.0,20.0$, and $40.0 \mu \mathrm{M} \mathrm{P}_{\mathrm{i}}$ in $2.4 \mathrm{~mL}$ of water in glass tubes. $0.8 \mathrm{~mL}$ of $3 \mathrm{~N} \mathrm{H}_{2} \mathrm{SO}_{4}$ was added to each standard tube. $0.4 \mathrm{~mL}$ of $2.5 \%(\mathrm{w} / \mathrm{v})$ ammonium molybdate (prepared in $3 \mathrm{~N} \mathrm{H}_{2} \mathrm{SO}_{4}$ ) was added in each tube. Last, $0.4 \mathrm{~mL}$ of reducing agents $(20 \mathrm{mg}$ of hydrazine sulfate and $20 \mathrm{mg}$ of ascorbic acid dissolved in $1 \mathrm{~mL}$ of $0.1 \mathrm{~N} \mathrm{H}_{2} \mathrm{SO}_{4}$ ) was added to each tube. After $2 \mathrm{~h}$ at room temperature, $\mathrm{A}_{820}$ was determined and plotted to generate a standard curve. $\mathrm{C}+\mathrm{Y}$ broth (no added $\mathrm{P}_{\mathrm{i}}$ ) was diluted $100 \mathrm{X}$ with water, $\mathrm{P}_{\mathrm{i}}$ content was assayed as described above, and $\mathrm{P}_{\mathrm{i}}$ concentration was determined from the standard curve.

\section{$P_{\mathrm{i}}$ Uptake Assays}

To study high $\mathrm{P}_{\mathrm{i}}$ conditions, strains were grown in $5 \mathrm{~mL}$ of $\mathrm{BHI}$ broth to $\mathrm{OD}_{600} \approx 0.2$. Cells were centrifuged at $5125 \times g$ for $5 \mathrm{~min}$ at room temperature, washed twice with $5 \mathrm{~mL}$ of $\mathrm{mCDM}$ lacking $\mathrm{P}_{\mathrm{i}}$, and resuspended at room temperature in $5 \mathrm{~mL}$ of $\mathrm{mCDM}$ lacking $\mathrm{P}_{\mathrm{i}} . \mathrm{K}_{2} \mathrm{H}^{32} \mathrm{PO}_{4}\left(10^{7}-10^{8} \mathrm{dpm} ; 8500-9120 \mathrm{Ci} / \mathrm{mmole}\right.$; Perkin Elmer) was added to a final concentration of $1 \mathrm{mM}$ at $t=0$, and $100 \mu \mathrm{L}$ of cells was collected by vacuum filtration $(0.22 \mu \mathrm{m}$ GSWP; $13 \mathrm{~mm}$ diameter; Millipore) at 1, 2, 4, 6, 10 min after addition of ${ }^{32} \mathrm{P}$. Filters were washed $3 \mathrm{X}$ with $3 \mathrm{~mL}$ of roomtemperature $1 \times$ PBS (Ambion). Washed filters were transferred individually into 20 - $\mathrm{mL}$ glass scintillation vials to which $5 \mathrm{~mL}$ of a biodegradable counting cocktail was added. Dpm of each sample was determined using a TRI-CARB 2100TR Liquid Scintillation Counter (Perkin Elmer), $\mathrm{P}_{\mathrm{i}}$ amount incorporated at each time point was calculated.

To study low $\mathrm{P}_{\mathrm{i}}$ condition, strains were grown to $\mathrm{OD}_{600} \approx 0.2$ in $\mathrm{mCDM}$ containing $36.4 \mathrm{mM} \mathrm{Pi}$ as described above. Cells were centrifuged at $5125 \times \mathrm{g}$ for $5 \mathrm{~min}$ at room temperature, and washed twice with $5 \mathrm{~mL}$ of $\mathrm{mCDM}$ lacking $\mathrm{P}_{\mathrm{i}}$. Cell pellets were resuspended in $5 \mathrm{~mL}$ of $\mathrm{mCDM}$ lacking $\mathrm{P}_{\mathrm{i}}$ and incubated $1 \mathrm{~h}$ at $37^{\circ} \mathrm{C}$ in an atmosphere of $5 \% \mathrm{CO}_{2} .200 \mu \mathrm{M}$ of $\mathrm{K}_{2} \mathrm{H}^{32} \mathrm{PO}_{4}\left(10^{7}-10^{8} \mathrm{dpm}\right)$ was added at $t=0$, and samples were withdrawn, filtered, and counted as described above. 


\section{RESULTS}

\section{$\Delta$ phoU2 Mutants Show a Growth Defect and Increased Sensitivity to a Range of Antibiotics That is Reversed by Inactivation of Pst2 Transport}

The Pst transporter is not needed for growth of E. coli at high $\mathrm{P}_{\mathrm{i}}$ concentrations $>4 \mu \mathrm{M}$, and $\Delta p h o U$ mutations lead to a severe growth defect that is reversed by inactivation of the Pst transporter (Steed and Wanner, 1993; Rice et al., 2009). To determine the roles of the Pst 1 and Pst 2 transporters and their regulation, we constructed a series of markerless deletion mutants [ $\Delta$ phoU2 (IU6375); $\Delta p h o U 1$ (IU6377); $\Delta p n p R S$ (IU6381); $\Delta$ pst2 (IU6610); $\Delta$ pst1 (IU6638)] in S. pneumoniae serotype 2 strain D39, which is encapsulated and virulent (Lanie et al., 2007; Figure 1, Table S1). Mutants were first grown in BHI broth, which contains a high $\mathrm{P}_{\mathrm{i}}$ concentration $(\approx 18 \mathrm{mM})$. Only the $\Delta$ phoU2 mutant showed a significant decrease in growth yield compared to the parent and other mutants (Figure 2A, Figure S1A, Table S4). Growth yield was restored when the $\triangle$ phoU2 mutation was complemented by an ectopic copy of the phoU $2^{+}$gene expressed from the $\mathrm{P}_{f t s A}$ promoter at the bgaA site (IU6397) (Figure 2A, Table S4). Similar results were obtained in mutants in unencapsulated D39 derivative strain K579 and E579 (data not shown).
Inactivation of phoU in E. coli generates higher sensitivity to various kinds of antibiotics than the parent strain ( $\mathrm{Li}$ and Zhang, 2007). Since the pneumococcal $\Delta$ phoU2 mutant shows a similar growth defect as the $\Delta p h o U$ mutant in E. coli (Figure 2A, Figure S1A), we tested antibiotic sensitivity to several antibiotics. Of the Pho regulon mutants tested in the encapsulated strain, only the $\Delta$ phoU2 mutant showed increased sensitivity to $\beta$-lactams and other classes of antibiotics, including glycopeptides and protein synthesis inhibitors, on plates that contain relatively high $\mathrm{P}_{\mathrm{i}}$ content (Figure 2B, Figure S1B, and Table S5).

Previous work in E. coli (Steed and Wanner, 1993; Wanner, 1996; Rice et al., 2009; Hsieh and Wanner, 2010) and C. crescentus, in which PhoU is essential for growth (Lubin et al., 2016), indicated that the reduced growth of phoU deletion or depletion mutants could be reversed by inactivation of the Pst pump. This reversal was interpreted to mean that PhoU negatively regulates the Pst transporter itself, and in its absence, deleterious phosphate compounds accumulate that disrupt growth and metabolism. In the pneumococcal encapsulated D39 genetic background, a $\Delta$ pst2-phoU2 deletion mutant lacking the Pst2 transporter and PhoU2 regulator grew similar to the parent strain and did not show increased sensitivity to antibiotics caused by the absence of PhoU2 alone (Figures 2C,D, Table S4). Likewise, single deletions of genes encoding each component of the Pst2 transporter restored growth yield of a $\Delta$ phoU2
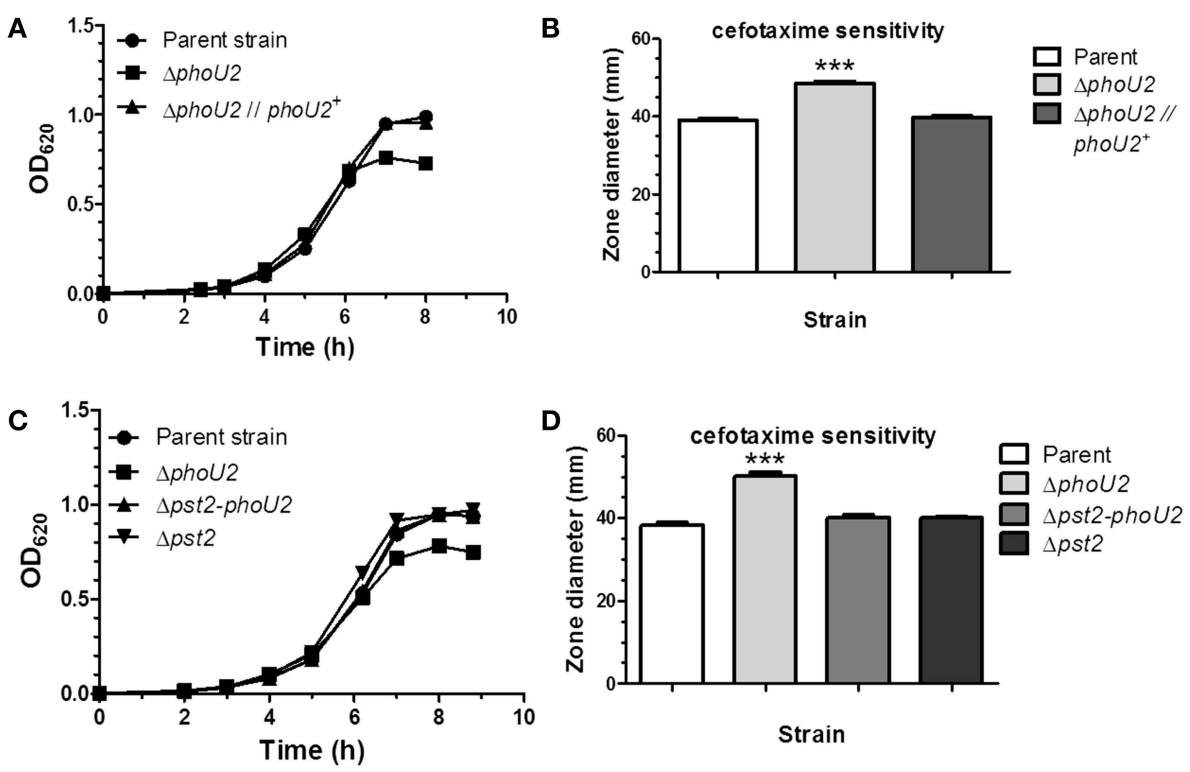

FIGURE 2 | Deletion of phoU2 leads to a lower growth yield and increased $\beta$-lactam antibiotic sensitivity that are reversed by a $\Delta p s t 2$ mutation. (A) Representative growth curves in $\mathrm{BHI}$ broth ( $\approx 18 \mathrm{mM} \mathrm{P}$ ) of encapsulated parent strain (IU1781), a $\Delta$ phoU2 mutant (IU6375), and a $\Delta$ phoU2 mutant complemented by ectopic expression of $\mathrm{PhoU}_{2}{ }^{+}$(IU6397). Strains were grown as described in Materials and Methods. A linear scale for $\mathrm{OD}_{620}$ is used to emphasize differences in growth yields. Growth yields and rates are quantitated for multiple determinations in Table S4. (B) Cefotaxime sensitivity assays of encapsulated parent strain (IU1781), a $\Delta$ phoU2 mutant (IU6375), and a PhoU2 ${ }^{+}$-complemented $\Delta$ phoU2 mutant (IU6397). Cefotaxime disk sensitivity assays of bacteria grown in BHI broth were performed as described in Material and Methods. P-values were calculated by unpaired $t$-tests relative to the parent strain using GraphPad Prism; $(n \geq 3)$;

${ }^{* \star *} P<0.001$. Increased sensitivity to other $\beta$-lactam antibiotics, vancomycin, gentamicin, and tetracycline of a $\Delta p h o U 2$ mutant compared to its isogenic parent strain is shown in Table S5. (C) Representative growth curves of encapsulated parent strain (IU1781) and $\Delta$ phoU2 (IU6375), $\Delta$ pst2-phoU2 (IU6550), and $\Delta$ pst2 (IU6610) mutants in BHI broth. (D) Cefotaxime sensitivity assays for encapsulated parent strain (IU1781), and $\Delta$ phoU2 (IU6375), $\Delta$ pst2-phoU2 (IU6550), and $\Delta$ pst2 (IU6610) mutants. $(n \geq 3) ;{ }^{\star \star \star} P<0.001$ 
mutant back to wild-type (data not shown). Western blot analysis showed that the $\Delta$ phoU2 mutation did not change the cellular amount of the PstS2 transporter subunit fused to the HA epitope tag (Figure S3), and by inference the amount of the Pst2 transporter. We conclude that the decreased growth yield and antibiotic sensitivity of encapsulated pneumococcus $\Delta$ phoU2 mutants in high $\mathrm{P}_{\mathrm{i}}$ conditions are dependent on function of the Pst2 transporter, consistent with negative regulation of the Pst2 transporter by PhoU2.

\section{PhoU2 Negatively Regulates Transcription Activation of the pst1 Operon by the PnpRS TCS in High $P_{\mathbf{i}}$ Conditions}

As noted in the Introduction, PhoU negatively regulates the PhoBR TCS in E. coli, but not in C. crescentus (Hsieh and Wanner, 2010; Lubin et al., 2016). Consequently, we tested whether $\Delta p h o U 1$ or $\Delta p h o U 2$ deletions affected transcript levels of the pst 1 or pst 2 operons under high $\mathrm{P}_{\mathrm{i}}$ conditions (see Figure 1). We first performed RNA-Seq analyses of $\Delta$ phoU2::kanrpsL $L^{+}$and $\Delta$ phoU2::kanrpsL ${ }^{+} \quad \Delta p h o U 1:: \mathrm{P}_{\mathrm{c}}$-erm mutants growing in early-middle exponential phase in $\mathrm{BHI}$ broth, which contains a high $(18 \mathrm{mM})$ concentration of $\mathrm{P}_{\mathrm{i}}$ (Table S6). In both strains, only transcript amounts of the pst1 transporter operon, including phoU1 in the single mutant, were strongly induced $(\approx 22 \mathrm{X})$. The transcript amounts of the $p n p R S$ regulator and $p s t 2$ transporter operons were not induced, and the number of other genes in the Pho regulon appears to be limited in S. pneumoniae D39 (Table S6). Notably, pneumococcus encodes neither an alkaline phosphatase ( $p h o A)$ nor a pathway for synthesis of teichuronic acids lacking phosphate (Wanner, 1996; Botella et al., 2011, 2014). Besides the strong induction of pst1 operon transcription, there were small $(2-4 \mathrm{X})$ changes in the relative amounts of only a handful of other transcripts, including some corresponding to metabolic and stress-responsive genes, possibly reflecting the defective growth of these phoU2 mutants. In both mutants, one of the stronger responses was a decrease in the relative transcript amounts of the genes encoding the glycerol facilitator (GlpF) and glycerol kinase (GlpK). A putative, somewhat degenerate Pho box is located -125 bp upstream of the $g l p K$ reading frame. Together, these results suggested that PhoU2 negatively regulates pst1 operon expression under high $\mathrm{P}_{\mathrm{i}}$ conditions, whereas the $p n p R S$ and $p s t 2$ operons are constitutively expressed.

These conclusions were confirmed by qRT-PCR analysis of combinations of markerless deletion mutations in the pst and pnpRS genes (Table 1). RNA-Seq transcriptome analysis indicates that the pnpRS, pst1-phoU1, and pst2-phoU2 operons are separately transcribed (Table S6, Figure 1, Figures S2A,B). Hence, we quantitated the relative amounts of the $p n p R$, $p s t S 1$, and $p s t S 2$ transcripts normalized to gyrA transcript amount by qRT-PCR to represent $p n p R S$, pst1-phoU1, and pst2-phoU2 operon expression (see Materials and Methods; Wayne et al., 2012). Consistent with the RNA-Seq results, the $\Delta$ phoU 2 mutations caused $\approx 16 \mathrm{X}$ increase in pst1-phoU1 operon transcript amount, but no change in expression of $p s t 2$ or pnpRS operon (Table 1, line 2). In contrast, a $\Delta p h o U 1$ mutation did not cause a significant change in the relative amounts of transcript from any of the three operons (Table 1, line 3). No increase in pst1-phoU1 transcript

TABLE 1 | Relative transcript amounts of the pst1, pst2, and pnpRS operons in regulatory mutants ${ }^{\mathrm{a}}$.

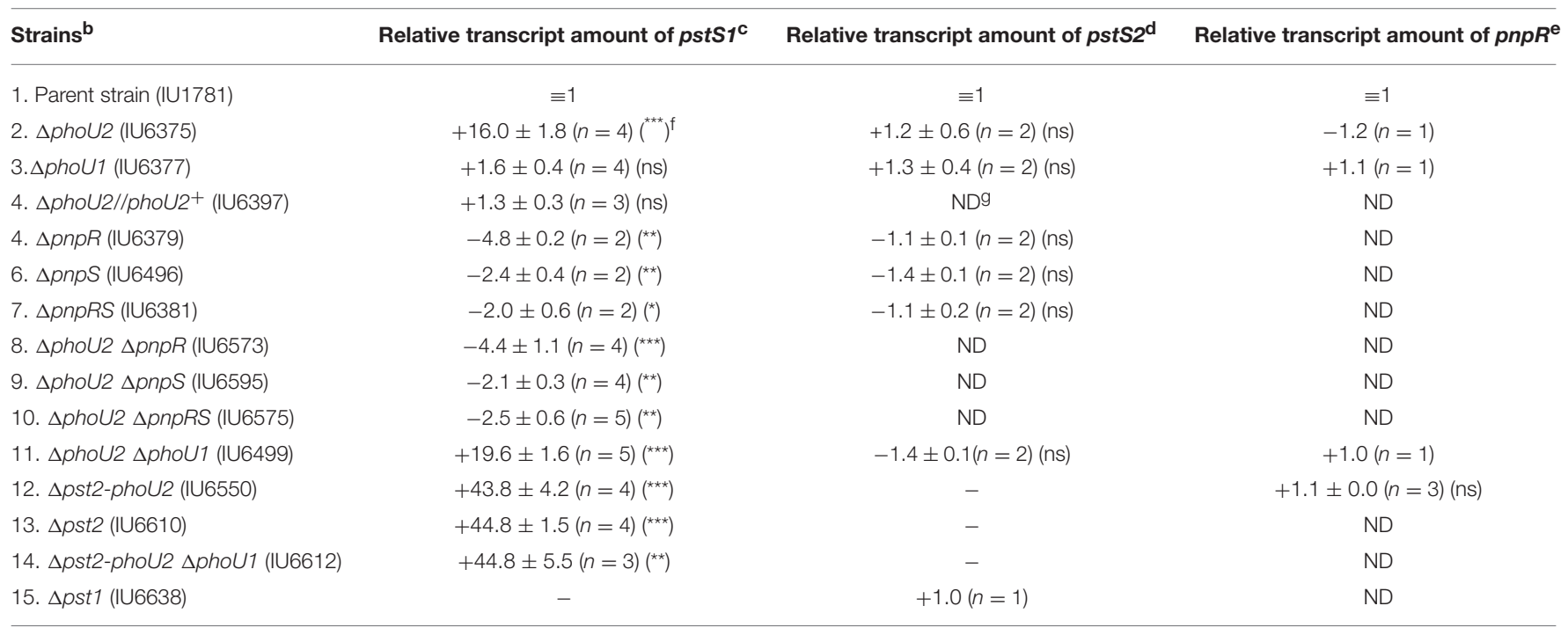

${ }^{a}$ RNA preparation and qRT-PCR were performed as described in Materials and Methods.

${ }^{b}$ Strains were markerless deletion mutants derived from encapsulated parent strain IU1781.

${ }^{c}$ Relative pstS1 gene transcript amount was used to represent pst1 operon expression.

${ }^{d}$ Relative pstS2 gene transcript amount was used to represent pst2 operon expression.

${ }^{e}$ Relative pnpR gene transcript amount was used to represent pnpRS operon expression.

$f_{\star \star \star *} P<0.001 ;{ }^{* *} P<0.01 ;{ }^{*} P<0.05$; ns, not significant. P-values were calculated by an unpaired $t$-test in GraphPad Prism. P-value is not available when $n=1$.

${ }_{9} N D$, not determined. 
amount in the $\Delta p h o U 2$ mutant was detected in complementation experiments in which a wild-type copy of $p h o U 2^{+}$was expressed from an ectopic site (Table 1, line 4).

We next determined that the increased transcription of the pst1-phoU1 operon in the $\Delta$ phoU2 mutant is mediated by the PnpRS TCS through increased phosphorylation of the PnpR $\sim \mathrm{P}$ RR. $\triangle p n p R, \Delta p n p S$, or $\triangle p n p R S$ mutants showed slightly reduced pst1-phoU1 operon transcript amounts compared to the parent strain, with no change in pst2-phoU2 operon expression (Table 1, lines 5-7). Likewise, $\Delta p n p R \Delta p h o U 2, \Delta p n p S \Delta p h o U 2$, and $\triangle p n p R S \Delta$ phoU2 double mutants showed reduced pst1-phoU1 operon relative transcript amounts (Table 1, lines 8-10), instead of the sizable increase observed for the $\Delta$ phoU2 single mutant containing an active PnpRS TCS (Table 1, line 2). To confirm directly that PhoU2 acts as a negative regulator of PnpRS function under high $\mathrm{P}_{\mathrm{i}}$ conditions, we performed Phos-tag SDS PAGE analysis to determine PnpR P RR phosphorylation levels (see Materials and Methods; Figure 3). In these experiments, we fused three tandem copies of the FLAG epitope tag to the Cterminus of the PnpR RR regulator expressed from its normal chromosomal locus (Figure 3, Table S1). The PnpR-L-FLAG ${ }^{3}$ $\mathrm{RR}$ induced pst1-phoU1 transcription to a similar extent as wild-type (untagged) $\mathrm{PnpR}^{+}$in a $\Delta p h o U 2$ mutant (data not shown). In the phoU2 $2^{+}$strain, essentially no PnpR P $(<1 \%)$ was detected in cells growing exponentially in high- $\mathrm{P}_{\mathrm{i}} \mathrm{BHI}$ broth (Figure 3). In contrast, the $\triangle$ phoU2 mutant contained $\approx 45 \%$ PnpR $\sim$ P, which accounts for the high $(\approx 16 \mathrm{X})$ increase in pst1phoU1 transcript detected (Table 1, line 2). We conclude that PhoU2 negatively regulates $\mathrm{PnpR} \sim \mathrm{P}$ amounts and transcription of the pst1-phoU1 operon, but does not regulate transcription of the pnpRS or pst2-phoU2 operon, which are constitutively expressed.
Consistent with this interpretation, a putative $\mathrm{PnpR} \sim \mathrm{P}$ binding site (Pho-box) sequence (TTTACACAATCTTTACA; Martin, 2004) is located 92 bp upstream of pstS1 reading frame gene (Figure 1), but no recognizable Pho-box sequences can be found upstream of the $p n p R S$ or pst2-phoU2 operon. Finally, we tested whether induction of pst1-phoU1 operon expression contributes to the growth defect and antibiotic sensitivity of a $\Delta p h o U 2$ mutant (Figure 2). A $\Delta$ phoU2 $\Delta p s t 1$ or $\Delta p h o U 2 \Delta p s t 1$ phoU1 double mutant showed the same decrease in growth yield (Figure 4A, Table S4) and antibiotic sensitivity (Figure 4B) as the $\Delta$ phoU2 single mutant, indicating that these defects were caused primarily by misregulation of the Pst 2 transporter in high $\mathrm{P}_{\mathrm{i}}$ conditions, instead of induced expression of the Pst1 transporter.

\section{Transcription of the pst1 Operon is Further Induced by the Absence of the Pst2 Transporter Under High $\mathbf{P}_{\mathbf{i}}$ Conditions}

We next tested whether absence of the Pst2 transporter affects pst1 operon expression in bacteria growing in high $\mathrm{P}_{\mathrm{i}}-\mathrm{BHI}$ broth. Surprisingly, relative transcript amounts from the pst1 operon increased by $\approx 44$ fold in the $\Delta p s t 2$ phoU2 ${ }^{+}, \Delta p s t 2-$ phoU2, and $\Delta$ pst2-phoU2 $\Delta$ phoU1 mutant compared to the parent strain (Table 1, lines 12, 13, and 14). By contrast, pst 2 operon transcription is unchanged in a $\Delta$ pst 1 phoU1 $1^{+}$ mutant compared to the parent (Table 1, line 15). The similar induction in the $\Delta p s t 2$ phoU2 ${ }^{+}$and $\Delta p s t 2-p h o U 2$ mutants (Table 1, lines 12 and 13) implies that negative regulation of the PnpRS TCS by PhoU2 depends on a functional Pst 2 transporter system. Moreover, the similarity of pst1 induction in the $\Delta p s t 2-$ phoU2 $\Delta$ phoU1 and other mutants implies that PhoU1 does not directly regulate pst1 transcription. This conclusion was supported by the similar induction of pst 1 operon transcription

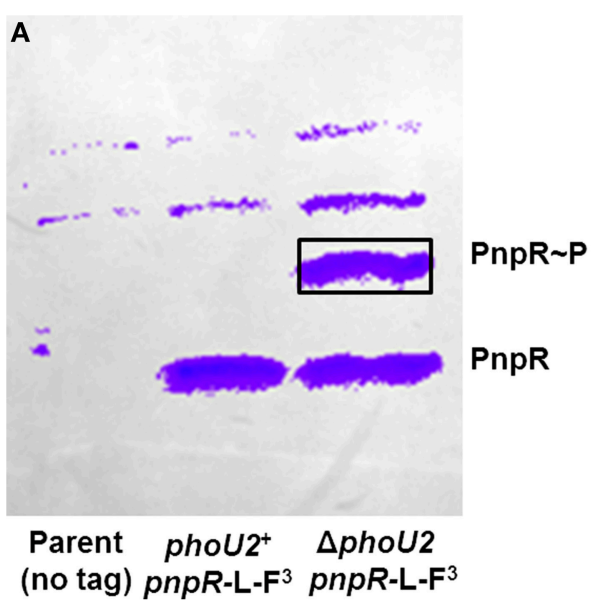

B

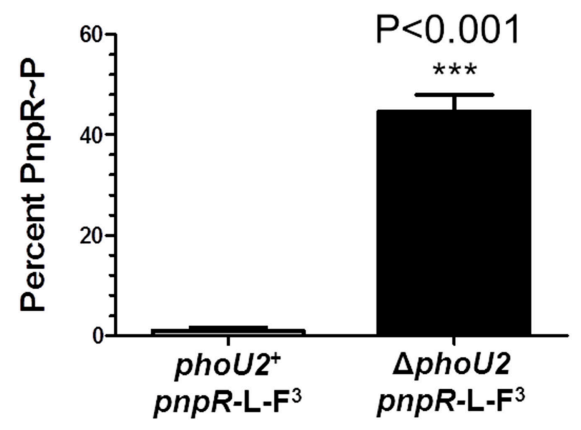

FIGURE 3 | Approximately $\mathbf{4 5} \%$ of PnpR is phosphorylated (PnpR P) in a $\Delta$ phoU2 mutant. (A) Representative Phos-tag SDS-PAGE of the encapsulated parent strain not expressing a FLAG-tagged protein (IU1781, lane 1) and of the pnpR-L-FLAG ${ }^{3}$ (IU6689, lane 2), and $\Delta$ phoU2 pnpR-L-FLAG ${ }^{3}$ (IU6687, lane 3) mutants growing exponentially in BHI broth. The gel was Western blotted with anti-FLAG antibody as described in Materials and Methods. The top two bands in all lanes are nonspecific. The upper anti-FLAG-specific band corresponds to phosphorylated PnpR P, and the lower band corresponds to unphosphorylated PnpR. Control experiments show that the upper band is heat-sensitive, as expected for PnpR P (Figure S4). (B) Quantification of 3 independent Phos-tag SDS-PAGE experiments. Less than $1 \%$ of PnpR was phosphorylated in the phoU2 ${ }^{+}$strain, whereas $\approx 45 \%$ of PnpR is phosphorylated (PnpR P) in the $\Delta p h o U 2$ mutant. P-value was determined by an unpaired $t$-test in GraphPad Prism; ${ }^{\star \star * P}<0.001$. 


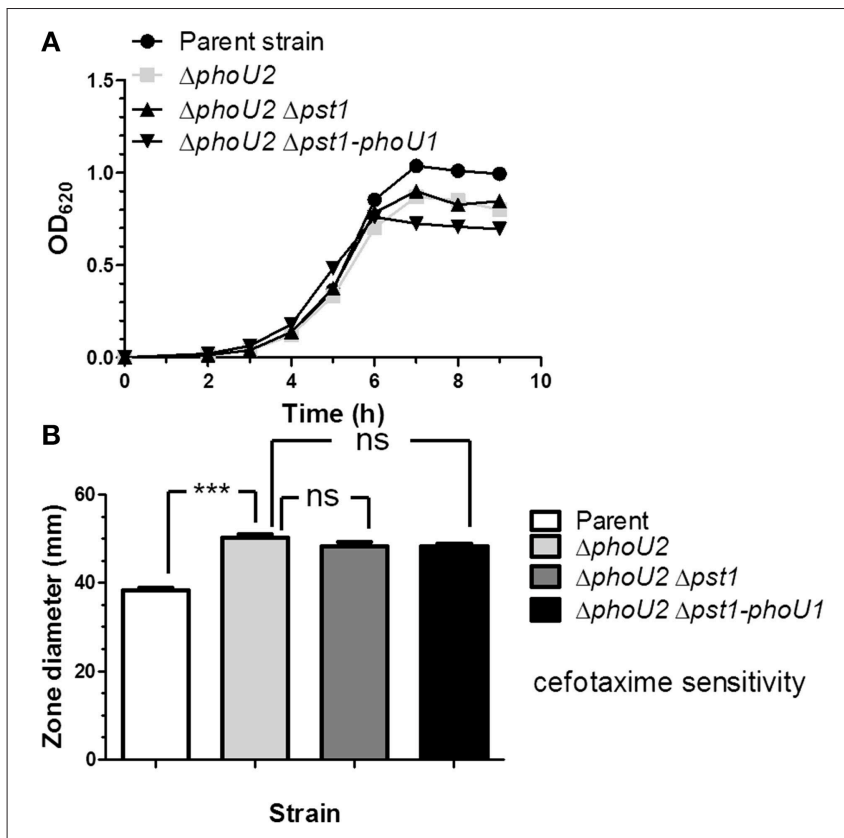

FIGURE 4 | Deletion of pst1 or pst1-phoU1 in a $\Delta$ phoU2 mutant does not recover growth yield or antibiotic sensitivity. (A) Representative growth curves of encapsulated parent strain (IU1781), and $\Delta$ phoU2 (IU6375), $\Delta$ phoU2 $\Delta$ pst1 (IU6664), and $\Delta$ phoU2 $\Delta$ pst1-phoU1 (IU6854) mutants in BHI broth. Growth yields and rates are quantitated in Table S4. (B) Cefotaxime sensitivity assays for encapsulated parent strain (IU1781), and $\Delta$ phoU2 (IU6375), $\Delta$ phoU2 $\Delta$ pst1 (IU6664), and $\Delta$ phoU2 spst1-phoU1 (IU6854) mutants. ( $n \geq 3$ ); ${ }^{* \star} P<0.001$. See Materials and Methods, the legend to Figure 2, and the text for additional details.

in the $\Delta$ phoU2 phoU1 $1^{+}$and $\Delta$ phoU2 $\Delta$ phoU1 mutants (Table 1, lines 2 and 11). Instead, the growth characteristics of these mutants imply that PhoU1 negatively regulates the activity of the Pst1 transporter, in parallel to the negative regulation of the activity of Pst2 by PhoU2 (Figure 5A, Table S4). In BHI broth, the parent, $\Delta p h o U 1$, and $\Delta$ pst2-phoU2 mutant show similar growth and antibiotic sensitivity (Figure 5; Table S4). In contrast, the $\Delta p h o U 2$ and $\Delta p h o U 1 \Delta$ st2-phoU2 mutants showed reduced growth yield and increased antibiotic sensitivity (Figure 5, Table S4), consistent with increased $\mathrm{P}_{\mathrm{i}}$ accumulation caused by misregulation of the Pst 2 and Pst 1 transporters, respectively. This interpretation was further supported by the reduced growth rate and yield and increased antibiotic sensitivity of the $\Delta$ phoU2 $\Delta$ phoU1 mutant compared to the $\Delta p h o U 2$ and $\Delta$ pst2-phoU2 $\Delta$ phoU1 mutants (Figure 5; Table S4).

\section{Either the Pst1 or Pst2 Transporter is Required in the Encapsulated, But Not in the Unencapsulated, D39 Strain}

E. coli encodes an alternate low-affinity $\mathrm{P}_{\mathrm{i}}$ uptake (Pit) system that functions in the absence of the high-affinity Pst transporter in high $\mathrm{P}_{\mathrm{i}}$ conditions (Wanner, 1996; Harris et al., 2001; Hsieh and Wanner, 2010). However, we were unable to construct $\Delta p s t 2$ $\Delta$ pst1 mutants in the encapsulated strain of D39 (Table 2, top two sections), where the $\Delta n p t A$ amplicon was used as a positive

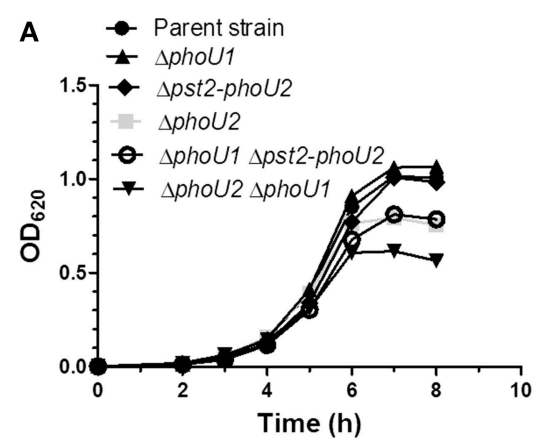

B

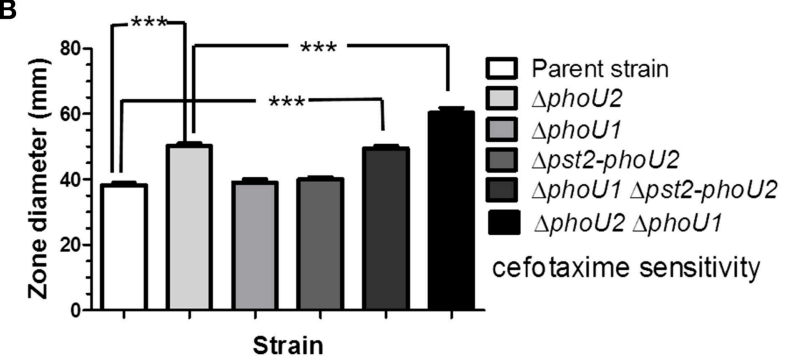

FIGURE 5 | A $\Delta$ phoU1 $\Delta$ pst2-phoU2 double mutant phenocopies a $\Delta$ phoU2 single mutant for decreased growth yield and increased cefotaxime sensitivity, which are even greater in a $\Delta$ phoU1 $\Delta$ phoU2 double mutant. (A) Representative growth curves of encapsulated parent strain (IU1781) and $\Delta$ phoU2 (IU6375), $\Delta$ phoU1 (IU6377), $\Delta$ pst2-phoU2 (IU6550), sphoU1 spst2-phoU2 (IU6612), and sphoU2 sphoU1 (IU6499) mutants in $\mathrm{BHI}$ broth. $(n \geq 3)$ Growth yields and rates are quantitated in Table S4. (B) Cefotaxime sensitivity assays for encapsulated parent strain (IU1781) and $\Delta$ phoU2 (IU6375), $\Delta$ phoU1 (IU6377), $\Delta$ pst2-phoU2 (IU6550), $\Delta$ phoU1 $\Delta$ pst2-phoU2 (IU6612), and $\Delta$ phoU2 $\Delta$ phoU1 (IU6499) mutants. ( $n \geq 3$ ); ${ }^{\star \star \star} P<0.001$. See Materials and Methods, the legend to Figure 2, and the text for additional details.

control in the transformations. Likewise, we were unable to construct a $\Delta p s t 2 \Delta p n p R S$ double mutant, where induction of the Pst1 transporter was negated by the absence of the PnpRS TCS (Table 1, top section; Figure 1). As expected, the cps ${ }^{+}$ $\triangle p n p R S$-pst1 mutant could be constructed (IU6133), where the Pst2 transporter is functional.

In all $\Delta p s t 2 \Delta p s t 1$ cps $^{+}$transformations, several colonies $(<10)$ appeared upon prolonged incubation (Table 2, top two sections). These suppressor colonies had a rougher appearance than the smooth colonies of D39 $\mathrm{cps}^{+}$strains (data not shown), suggesting that capsule production was lost or reduced in these $\Delta$ pst2 $\Delta$ pst1 transformants. The Quellung test for serotype 2 capsule (see Materials and Methods) confirmed that a suppressor strain (IU6413) had lost its capsule (data not shown). This result suggested that unlike in $c p s^{+}$strains, we would be able to construct $\Delta c p s \Delta p s t 1 \Delta p s t 2$ mutants in the D39 genetic background. This hypothesis was confirmed by transformation experiments (Table 2, bottom two sections), and growth experiments showing that $\Delta c p s \Delta p s t 1 \Delta p s t 2$ triple mutants grew comparably to the $\Delta c p s$ single mutant in BHI broth (Figure S5). Thus, we conclude that either the Pst1 or Pst2 $\mathrm{P}_{\mathrm{i}}$ transporter must be functional in encapsulated D39 strains and that the $\Delta$ pst1 $\Delta p s t 2 c p s^{+}$double mutant is not viable. 
TABLE 2 | The $\Delta$ pst1 $\Delta$ pst2 double mutant cannot be constructed in encapsulated strain $\mathrm{D} 39^{\mathrm{a}}$.

\begin{tabular}{|c|c|c|}
\hline Recipient strain ${ }^{b}$ & Amplicon ${ }^{c}$ & $\begin{array}{l}\text { Number of colonies on } \\
\text { transformation plates } \\
\text { after } \approx 20 \mathrm{~h}^{\mathrm{d}}\end{array}$ \\
\hline \multirow{5}{*}{$\begin{array}{l}\Delta p s t 2 \text { cps }^{+} \\
\text {(encapsulated) }\end{array}$} & $\Delta n p t A$ (control) & $100-150(n=3)$ \\
\hline & $\Delta p n p R S$ & $0-10(n=3)$ \\
\hline & $\Delta p s t 1$ & $0-4(n=3)$ \\
\hline & $\Delta p s t 1-p h o U 1$ & $0(n=3)$ \\
\hline & No DNA (control) & $0(n=3)$ \\
\hline \multirow{4}{*}{$\begin{array}{l}\Delta p s t 1 \text { cps }^{+} \\
\text {(encapsulated) }\end{array}$} & $\Delta n p t A$ (control) & $100-150(n=3)$ \\
\hline & $\Delta p s t 2$ & $0(n=3)$ \\
\hline & $\Delta p s t 2-p h o U 2$ & $0(n=3)$ \\
\hline & No DNA (control) & $0(n=3)$ \\
\hline \multirow{5}{*}{$\begin{array}{l}\text { spst2 cps mutants } \\
\text { (unencapsulated) }\end{array}$} & $\Delta n p t A$ (control) & $100-150(n=3)$ \\
\hline & $\Delta p n p R S$ & $250-300(n=3)$ \\
\hline & $\Delta p s t 1$ & $100-150(n=3)$ \\
\hline & $\Delta p s t 1-p h o U 1$ & $250-300(n=3)$ \\
\hline & No DNA (control) & $0(n=3)$ \\
\hline \multirow{4}{*}{$\begin{array}{l}\Delta p s t 1 \text { cps mutants } \\
\text { (unencapsulated) }\end{array}$} & $\Delta n p t A$ (control) & $100-150(n=3)$ \\
\hline & $\Delta p s t 2$ & $100-150(n=3)$ \\
\hline & $\Delta$ pst2-phoU2 & $150-200(n=3)$ \\
\hline & No DNA (control) & $0(n=3)$ \\
\hline
\end{tabular}

${ }^{a}$ Transformations were performed as described in Materials and Methods.

${ }^{b}$ Transformations were performed into multiple cps $^{+}$strains [IU1690 (D39); IU1781 (D39 rpsL1)] and cps mutants [IU1824 (D39 $\Delta$ cps rpsL1); IU1945 (D39 $\Delta$ cps); IU3309 (D39 $\Delta c p s 2 E$ rpsL1)] with similar results. D39 $\Delta$ cps2E rpsL1 $\Delta$ pst1 $\Delta$ pst2 mutants could not be repaired back to $\mathrm{cps}^{+}$(data not shown).

${ }^{c}$ Amplicons were synthesized as described in Materials and Methods (see Table S2). Amplicons used for transformations contained the $P_{C}$-kanrps $L^{+}$or $P_{C}$-erm antibiotic cassette for selection. Transformations with the $\triangle n p t A$ amplicon or without DNA were the positive or negative control, respectively.

$d \leq 10$ colonies on plates indicates accumulation of unencapsulated suppressor mutants (see text).

\section{NptA is the Third $P_{\mathrm{i}}$ Uptake System That Functions in $\Delta$ cps $\Delta p s t 1 \Delta p s t 2$ Mutants}

Normal growth of the $\Delta$ cps $\Delta$ pst1 $\Delta$ pst2 mutant in high $\mathrm{P}_{\mathrm{i}}$ medium (Figure 5) implies that sufficient $P_{i}$ is being taken up by a third uptake system. BLAST searches did not reveal a close pneumococcal homolog of the Pit symporters of E. coli and B. subtilis. During these searches, we found another candidate gene, spd_0443, which encodes a putative $\mathrm{Na}^{+} / \mathrm{P}_{\mathrm{i}}$-cotransporter IIlike protein. Spd_0443 homologs have been shown to act as $\mathrm{P}_{\mathrm{i}}$ transporters in mammalian intestines and kidneys (Katai et al., 1999 ) and in certain bacterial species, such as $V$. cholerae and Vibrio vulnificus (Lebens et al., 2002; Staley and Harwood, 2014). Consistent with a role in $\mathrm{P}_{\mathrm{i}}$ uptake, we could not delete spd_0443 in a $\Delta$ cps $\Delta$ pst1 $\Delta$ pst2 mutant in high $\mathrm{P}_{\mathrm{i}}$ medium (Table 3), but we could delete spd_0443 in the $\Delta p s t 1$ or $\Delta p s t 2$ single mutant (Table 2). Thus, the Spd_0443 $\mathrm{Na}^{+} / \mathrm{P}_{\mathrm{i}}$-cotransporter likely acts as a third Pi uptake system in S. pneumoniae. Because the iron transporter in S. pneumoniae is already named "Pit," we renamed Spd_0443 as NptA $\left(\mathrm{Na}^{+}\right.$-dependent phosphate transporter $\left.\underline{\text { A}}\right)$, similar to Vibrio species (Lebens et al., 2002).
TABLE 3 | NptA ( $\mathrm{Na}^{+} / \mathrm{Pi}$ co-transporter) is a third $\mathrm{P}_{\mathrm{i}}$ uptake system.

\begin{tabular}{|c|c|c|}
\hline Recipient strain ${ }^{a}$ & Amplicon ${ }^{b}$ & $\begin{array}{l}\text { Number of colonies on } \\
\text { transformation plates after } \approx 20 \mathrm{~h}\end{array}$ \\
\hline \multirow[t]{3}{*}{$\Delta p s t 1 c p s$} & $\Delta p n p R$ (control) & $150-200(n=3)$ \\
\hline & $\Delta n p t A$ & $100-150(n=3)$ \\
\hline & No DNA (control) & $0(n=3)$ \\
\hline \multirow[t]{3}{*}{$\Delta p s t 2 c p s$} & $\Delta p n p R$ (control) & $150-200(n=3)$ \\
\hline & $\Delta n p t A$ & $100-150(n=3)$ \\
\hline & No DNA (control) & $0(n=3)$ \\
\hline \multirow[t]{3}{*}{$\Delta p s t 1 \Delta p s t 2 c p s$} & $\Delta p n p R$ (control) & $150-200(n=3)$ \\
\hline & $\Delta n p t A$ & $0(n=3)$ \\
\hline & No DNA (control) & $0(n=3)$ \\
\hline
\end{tabular}

${ }^{a}$ Transformations were performed as described in Materials and Methods. Transformations were performed into two cps mutants [IU1824 (D39 $\Delta$ cps rpsL1); IU3309 (D39 $\Delta$ cps2E rpsL1)] with similar results.

${ }^{b}$ Amplicons were synthesized as described in Materials and Methods (see Table S2). Amplicons used for transformations contained the $P_{C}$-kanrps $L^{+}$or $P_{C}$-erm antibiotic cassette for selection. Transformations with the $\triangle p n p R$ amplicon or without DNA were the positive and negative control, respectively.

\section{$\Delta p s t 1-p h o U 1$ or $\Delta$ pst2-phoU2 Deletion Has No Effect on Growth Under Low $P_{i}$ Conditions}

We next examined the roles of the Pst1 and Pst2 transporters and their regulators (Figure 1) under low $\mathrm{P}_{\mathrm{i}}$ culture conditions. A previous study used the semi-defined $\mathrm{C}+\mathrm{Y}$ medium as a low $\mathrm{P}_{\mathrm{i}}$ condition (Novak et al., 1999). However, encapsulated strains grew in $\mathrm{C}+\mathrm{Y}$ broth without $\mathrm{P}_{\mathrm{i}}$ addition (Figure S6), and direct chemical assay (see Materials and Methods; Katewa and Katyare, 2003) showed that $\mathrm{C}+\mathrm{Y}$ broth (with no added $\mathrm{P}_{\mathrm{i}}$ ) contains $\approx 1.5 \mathrm{mM} \mathrm{P} \mathrm{P}_{\mathrm{i}}$ (Figure S7). Therefore, a modified chemically defined medium (mCDM) was used to study low $P_{i}$ culture conditions (see Materials and Methods; Carvalho et al., 2013). The growth yield of the wild-type encapsulated strain was dependent on $P_{i}$ concentration below $1 \mathrm{mM} \mathrm{P} P_{i}$, with growth detectable down to $\approx 10 \mu \mathrm{M}$ and no growth without $\mathrm{P}_{\mathrm{i}}$ addition (Figure 6A). Growth rates and yields of the $\Delta p s t 2-$ phoU2 and $\Delta$ pst1-phoU1 mutants were similar to those of the parent strain (Figures 6B,C), implying that a functional Pst1 or Pst2 transporter is sufficient for optimal growth under low $\mathrm{P}_{\mathrm{i}}$ conditions.

We used unencapsulated $(\Delta c p s)$ mutants to determine the effects of $\mathrm{P}_{\mathrm{i}}$ concentration when both the Pst1 and Pst2 transporters were absent. Similar to the encapsulated strains (Figure 6), growth yield of the parent, $\Delta p s t 1-p h o U 1$, and $\Delta p s t 2-$ $\Delta$ phoU2 single mutants decreased below $1 \mathrm{mM} \mathrm{P}_{\mathrm{i}}$ and was still detectable at $10 \mu \mathrm{M} \mathrm{P}_{\mathrm{i}}$ (Figures 7A-C). By contrast, the growth of the $\Delta$ pst2-phoU2 $\Delta$ pst1-phoU1 double mutant was not fully supported even by $2 \mathrm{mM} \mathrm{P}_{\mathrm{i}}$, and growth yield showed apparent autolysis in $1 \mathrm{mM} \mathrm{P} \mathrm{P}_{\mathrm{i}}$ and no growth with $\geq 100 \mu \mathrm{M} \mathrm{P}$ (Figure 7D). We conclude that in low $\mathrm{P}_{\mathrm{i}}$ conditions, the NptA transporter alone is not sufficient for growth of D39-derived $S$. pneumoniae, consistent with NptA acting as a low-affinity $\mathrm{P}_{\mathrm{i}}$ transporter compared to Pst1 or Pst2. 


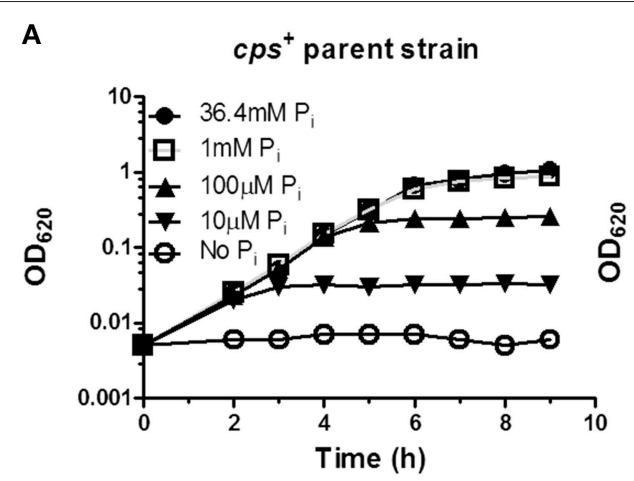

B

$c p s^{+} \Delta p s t 2-p h o U 2$

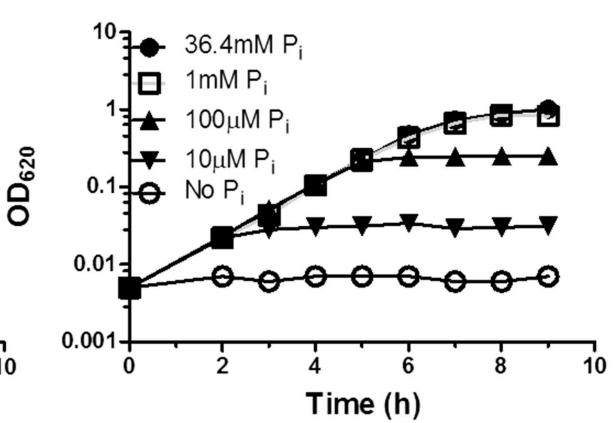

C

$\operatorname{cps}^{+} \Delta p s t 1-p h o U 1$

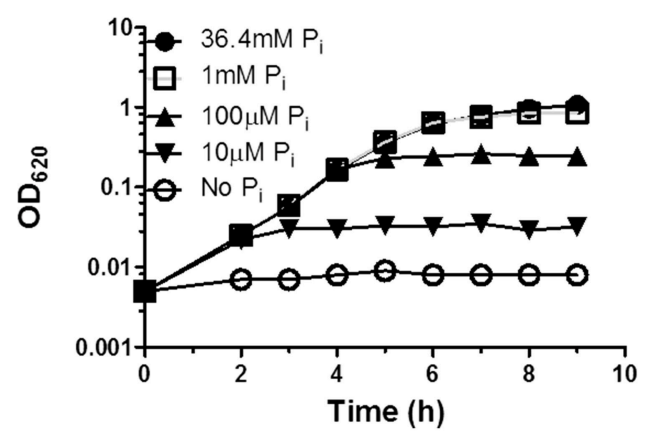

FIGURE 6 | Deletion of the pst1-phoU1 or pst2-phoU2 operon does not affect growth under low $\mathrm{P}_{\mathrm{i}}$ conditions in mCDM media. (A) Representative growth curves of encapsulated parent strain (IU1781) in mCDM with 36.4, $1 \mathrm{mM}, 100,10 \mu \mathrm{M}$, and no $\mathrm{P}_{\mathrm{i}}$. (B) Representative growth curves of a $\Delta$ pst2-phoU2 mutant (IU6550) in $\mathrm{mCDM}$ with 36.4, $1 \mathrm{mM}, 100,10 \mu \mathrm{M}$, and no $\mathrm{P}_{\mathrm{j}}$. (C) Representative growth curves of a $\Delta$ pst1-phoU1 mutant (IU6830) in mCDM with $36.4,1 \mathrm{mM}, 100,10 \mu \mathrm{M}$, and no $P_{i}$. mCDM with different concentrations of $P_{i}$ was prepared as described in Materials and Methods. Growth curves were determined at least $3 X$ independently.

\section{Low $P_{i}$ Induces pst1 Operon Transcript Amount $>100 \mathrm{X}$ via Phosphorylation of the PnpR P RR}

We determined the effect of low $\mathrm{P}_{\mathrm{i}}$ concentration on pst1 operon expression in the encapsulated D39 strain. Strains were grown in high- $\mathrm{P}_{\mathrm{i}}(36.4 \mathrm{mM}) \mathrm{mCDM}$, washed, and resuspended in $\mathrm{mCDM}$ containing high $(36.4 \mathrm{mM})$ or low $(10 \mu \mathrm{M}) \mathrm{P}_{\mathrm{i}}$ (see Materials and Methods). After $30 \mathrm{~min}$, samples were taken for qRT-PCR using $16 \mathrm{~S}$ rRNA as the normalization standard (see Materials and Methods). In all strains tested, $\mathrm{P}_{\mathrm{i}}$ limitation to $10 \mu \mathrm{M}$ induced relative $p s t 1$ transcript amount by $>100 \mathrm{X}$ compared to the wild-type parent strain in high $(36.4 \mathrm{mM}) \mathrm{P}_{\mathrm{i}}$ (Table 4). Similar to strains grown in BHI (Table 1), $\Delta$ phoU2 and $\Delta$ phoU2 $\Delta$ phoU1 mutants showed $\approx 25 \mathrm{X}$ induction of pst 1 operon transcript amount when grown in mCDM containing high $\mathrm{P}_{\mathrm{i}}$ (Table 4), whereas a $\Delta p h o U 1$ mutant showed no increase (Table 4). In these mutants, reduction of $\mathrm{P}_{\mathrm{i}}$ concentration to $10 \mu \mathrm{M}$ induced pst 1 transcript amounts by an additional $\approx 5-$ 100X (Table 4). $\mathrm{P}_{\mathrm{i}}$ limitation of a $\triangle p n p R S$ TCS mutant showed no increase in relative pst 1 operon transcript amounts (data not shown), indicating a dependence on the PnpRS TCS for induction of pst 1 operon transcription in low $\mathrm{P}_{\mathrm{i}}$ media. This conclusion was confirmed by Phos-tag SDS PAGE, which showed that phosphorylation of the PnpR RR (PnpR P) went from $<1 \%$ in $\mathrm{mCDM}$ containing $36.4 \mathrm{mM} \mathrm{P}_{\mathrm{i}}$ to $\approx 80 \%$ following a shift to $\mathrm{mCDM}$ lacking $\mathrm{P}_{\mathrm{i}}$ for $40 \mathrm{~min}$ (Figure $\mathrm{S} 8 \mathrm{~A}$ ). We conclude that transcription of pneumococcal pst1 transporter operon is strongly induced by the $\mathrm{PnpR} \sim \mathrm{P} R \mathrm{R}$ in low $\mathrm{P}_{\mathrm{i}}$ conditions.

\section{Deletion of pst1-phoU1 and pst2-phoU2 Reduces the Rate of $\mathrm{P}_{\mathrm{i}}$ Uptake by $\approx 50 \%$ in an Unencapsulated Strain}

Previously, the relative rate of $\mathrm{P}_{\mathrm{i}}$ uptake was reported to be reduced by $\approx 30 \%$ in a $\triangle p s t B 1$ mutant of laboratory strain $\mathrm{R} 6 \mathrm{x}$ grown in $\mathrm{C}+\mathrm{Y}$ medium (no added $\mathrm{P}_{\mathrm{i}}$ ) (Novak et al., 1999), which turns out to contain a relatively high $(1.5 \mathrm{mM}) \mathrm{P}_{\mathrm{i}}$ content (above; Figure S7). To the contrary, ${ }^{32} \mathrm{P}_{\mathrm{i}}$ uptake experiments in encapsulated and unencapsulated D39 mutants lacking the Pst1 ( $\Delta$ pst1-phoU1) or Pst2 ( $\Delta$ pst2-phoU2) transporter showed linear rates of ${ }^{32} \mathrm{P}_{\mathrm{i}}$ uptake for at least $10 \mathrm{~min}$ that were similar to those of the wild-type parent strains in $\mathrm{mCDM}$ containing $1 \mathrm{mM}$ total $\mathrm{P}_{\mathrm{i}}$ (Figures 8A,B, Table S7). R6x is a derivative of R6 (Tiraby and Fox, 1973), which is an unencapsulated derivative of D39 (Lanie et al., 2007). The difference between this and the previous result (Novak et al., 1999) may partly reflect the large number of mutations in the R6 laboratory strain compared to the D39 strain progenitor genetic background (Lanie et al., 2007). In contrast to the single mutants, the unencapsulated $\Delta$ pst1-phoU1 $\Delta p s t 2$ phoU2 double mutant showed a significant drop $(\approx 50 \%)$ in the rate of $\mathrm{P}_{\mathrm{i}}$ uptake compared to the wild-type parent strain or 

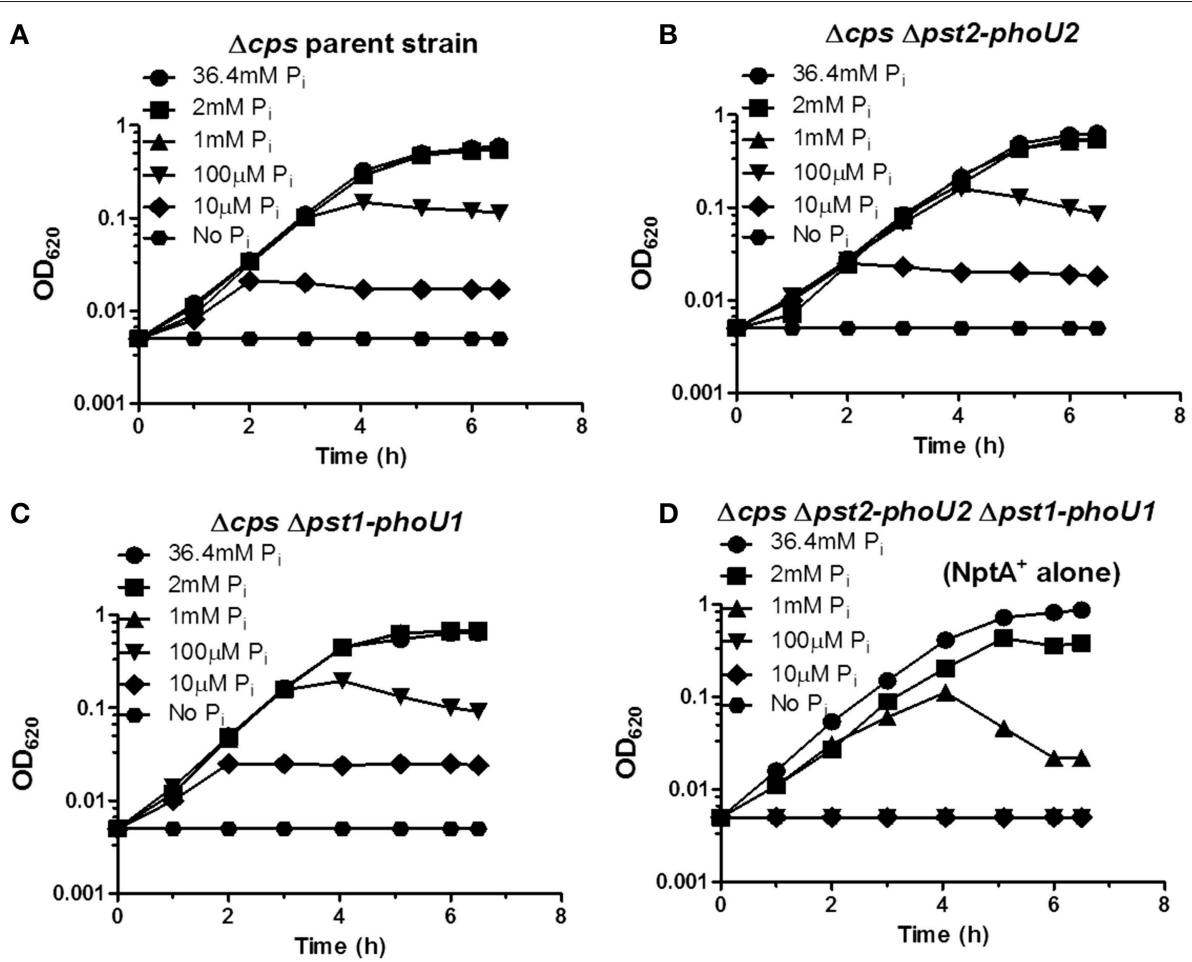

FIGURE 7 | The NptA Na+/ $\mathbf{P}_{\mathrm{i}}$ co-transporter alone cannot provide sufficient $\mathbf{P}_{\mathrm{i}}$ for long-term growth in $\mathrm{mCDM}$ containing moderately high (1 mM) and lower $\mathbf{P}_{\mathrm{i}}$ concentrations. (A) Representative growth curves of unencapsulated parent strain $\Delta c p s$ (IU1945) in mCDM with 36.4, 2, $1 \mathrm{mM}, 100,10 \mu \mathrm{M}$, and no $\mathrm{P}_{\mathrm{i}}$. (B) Representative growth curves of unencapsulated $\Delta c p s \Delta$ sst2-phoU2 mutant (K583) in mCDM with 36.4, 2, $1 \mathrm{mM}, 100,10 \mu \mathrm{M}$, and no $\mathrm{P}_{\mathrm{i}}$. (C) Representative growth curves of unencapsulated $\Delta c p s \Delta$ pst1-phoU1 mutant (E595) in mCDM with 36.4, 2, $1 \mathrm{mM}, 100,10 \mu \mathrm{M}$, and no $\mathrm{P}_{\mathrm{i}}$. (D) Representative growth curves of unencapsulated $\Delta$ cps $\Delta$ pst2-phoU2 $\Delta$ pst1-phoU1 mutant (IU5774), which only contains the NptA Na+/ $\mathrm{P}_{\mathrm{i}}$ transporter, in mCDM with 36.4, 2, $1 \mathrm{mM}, 100,10 \mu \mathrm{M}$, and no $\mathrm{P}_{\mathrm{i}}$. Growth curves were determined at least 3X independently.

the single mutants in $\mathrm{mCDM}$ containing $1 \mathrm{mM} \mathrm{P}_{\mathrm{i}}$ (Figure 8B, Table S7) or in $\mathrm{C}+\mathrm{Y}$ broth (data not shown). This result implicates both the Pst 1 and Pst 2 transporters in $\mathrm{P}_{\mathrm{i}}$ uptake in S. pneumoniae D39.

\section{$P_{i}$ Uptake is Reduced in a $\Delta p s t 1-p h o U 1$ Mutant Limited for Total $\mathbf{P}_{\mathbf{i}}$}

To determine $\mathrm{P}_{\mathrm{i}}$ uptake under low $\mathrm{P}_{\mathrm{i}}$ conditions, we incubated encapsulated parent, $\Delta$ pst1-phoU1, or $\Delta$ pst2-phoU2 mutants in $\mathrm{mCDM}$ lacking $\mathrm{P}_{\mathrm{i}}$ for $1 \mathrm{~h}$, and then added ${ }^{32} \mathrm{P}_{\mathrm{i}}$ (total $\left[\mathrm{P}_{\mathrm{i}}\right]$ $=200 \mu \mathrm{M}$ ), and sampled $\mathrm{P}_{\mathrm{i}}$ uptake with time (Figure $8 \mathrm{C}$ ). Unlike the constant rate of ${ }^{32} \mathrm{P}$ uptake observed at $1 \mathrm{mM}$ total $\mathrm{P}_{\mathrm{i}}$ (Figures 8A,B), $\mathrm{P}_{\mathrm{i}}$ uptake leveled off after about $5 \mathrm{~min}$ in $200 \mu \mathrm{M} \mathrm{P} \mathrm{P}_{\mathrm{i}}$ (Figure $8 \mathrm{C}$ ). The initial rate of $\mathrm{P}_{\mathrm{i}}$ uptake by the encapsulated parent strain was markedly greater $(\approx 8 \mathrm{X})$

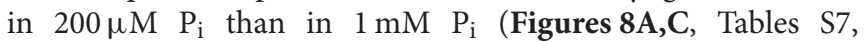
S8). The initial rate of $\mathrm{P}_{\mathrm{i}}$ uptake was comparable for the parent strain and the $\Delta$ pst2-phoU2 mutant (Figure 8C, Table $\mathrm{S} 8$ ). In contrast, the initial rate of $\mathrm{P}_{\mathrm{i}}$ uptake was reduced by $\approx 2 \mathrm{X}$ in the $\Delta$ pst1-phoU1 mutant compared to the parent or $\Delta$ pst2-phoU2 mutant (Figure 8C, Table S8). These results support a primary role for the Pstl transporter in low- $\mathrm{P}_{\mathrm{i}}$ conditions.

\section{DISCUSSION}

In this paper we demonstrate for the first time that regulation of the two evolutionarily distinct Pst $\mathrm{P}_{\mathrm{i}}$ transport systems is linked in several ways in the human commensal and pathogen, S. pneumoniae. Niches encountered by pneumococcus in human hosts contain different $\mathrm{P}_{\mathrm{i}}$ concentrations, including nasal fluid $(\approx 5 \mathrm{mM})$, saliva $(\approx 1 \mathrm{mM})$, and serum $(\approx 1 \mathrm{mM})$ (Bansal, 1990; Wilson, 2005, 2008). Several aspects of this regulatory network are unusual, compared to the usual negative regulation of $\mathrm{P}_{\mathrm{i}}$ uptake even at moderate $\mathrm{P}_{\mathrm{i}}$ concentrations in other bacterial species (Figure 1; Hulett, 1993; Hsieh and Wanner, 2010; Botella et al., 2011). The pst1-phoU1 and pst2-phoU2 operons are completely separated in the pneumococcal chromosome, and although upstream of the $p s t 1-p h o U 1$ operon, the $p n p R S$ operon, which encodes the PnpRS TCS, is independently expressed and not autoregulated (Table 1, Figure 1). Deletion of gene $s p d \_1614$, which encodes a third putative PhoU-like protein, did not lead to growth phenotypes and was not studied further (data not shown).

Expression of the Pst 2 transporter is constitutive under the conditions tested here, including media containing high $\mathrm{P}_{\mathrm{i}}$ concentrations (Table 1, Table S6, and Figure S3). However, Pst2 uptake of $\mathrm{P}_{\mathrm{i}}$ is likely negatively regulated by the PhoU2 protein, whose absence causes a drop in growth yield and 
TABLE 4 | Relative transcript amounts of the pst1 operon in different mutants in $\mathrm{mCDM}$ containing high and low $\mathrm{P}_{\mathrm{i}}$ concentrations ${ }^{\mathrm{a}}$.

\begin{tabular}{|c|c|c|}
\hline Strains ${ }^{b}$ & $\begin{array}{l}P_{i} \text { concentration } \\
\text { in } \mathrm{mCDM}\end{array}$ & $\begin{array}{l}\text { Relative transcript amount o } \\
\text { pstS1 operonc }\end{array}$ \\
\hline \multirow[t]{2}{*}{ Parent strain (IU1781) } & $36.4 \mathrm{mM}$ & $\equiv 1$ \\
\hline & $10 \mu \mathrm{M}$ & $209.7 \pm 37.9(n=6)\left(^{(* \star \star}\right)^{d}$ \\
\hline \multirow[t]{2}{*}{ sphoU2 (IU6375) } & $36.4 \mathrm{mM}$ & $24.1 \pm 3.9(n=3)\left({ }^{* \star \star}\right)$ \\
\hline & $10 \mu \mathrm{M}$ & $201.6 \pm 47.6(n=3)\left({ }^{* * *}\right)$ \\
\hline \multirow[t]{2}{*}{$\Delta$ phoU1 (IU6377) } & $36.4 \mathrm{mM}$ & $1.4 \pm 0.1(n=3)(n s)$ \\
\hline & $10 \mu \mathrm{M}$ & $145.4 \pm 25.3(n=4)\left(^{* * *}\right)$ \\
\hline \multirow{2}{*}{$\begin{array}{l}\Delta \text { phoU2 } \Delta \text { phoU1 } \\
\text { (IU6499) }\end{array}$} & $36.4 \mathrm{mM}$ & $28.3 \pm 0.5(n=3)\left(^{(* \star)}\right.$ \\
\hline & $10 \mu \mathrm{M}$ & $136.3 \pm 12.6(n=3)\left(^{* * *}\right)$ \\
\hline
\end{tabular}

${ }^{a} R N A$ preparation and GRT-PCR from strains in $\mathrm{MCDM}$ containing high and low $P_{i}$ concentrations were performed as described in Materials and Methods.

${ }^{b}$ Strains were markerless deletion mutants derived from encapsulated parent strain IU1781 (see Table S1).

${ }^{C}$ Relative pstS1 gene transcript amount was used to represent pst1 operon expression. ${ }^{d * * *} P<0.001$; ns, not significant. $P$-values were calculated by an unpaired $t$-test in GraphPad Prism

increased antibiotic sensitivity in mutants growing in high $\mathrm{P}_{\mathrm{i}}$ medium (Tables S4, S5, Figures 1, 2, and Figure S3). In addition, PhoU2 negatively regulates the transcription activation of the pst1-phoU1 operon by the phosphorylated PnpR $\sim \mathrm{P} R \mathrm{R}$, such that a $\Delta$ phoU2 deletion mutation leads to a substantial increase in pst1-phoU1 transcript amounts (Table 1, Figures 1, 3, and Figure S4). The PhoU1 protein, which shares only $34 \%$ amino acid identities with PhoU2, does not play a reciprocal role in negatively regulating pst1-phoU1 transcription (Table 1, lines 3, 11, and 14), but PhoU1 likely negatively regulates $P_{i}$ uptake by the Pst1, but not the Pst2, $P_{i}$ transporter (Figures 1, 4, 5). Thus, the PhoU2 protein can regulate both PnpR phosphorylation level and Pst2 transporter function, similar to the PhoU homolog in E. coli (Hsieh and Wanner, 2010; Gardner et al., 2014, 2015). In contrast, PhoU1 function is restricted to regulating transporter but not TCS function, similar to the PhoU in C. crescentus (Lubin et al., 2016). E. coli PhoU interacts with the PAS domain of the PhoR HK (Gardner et al., 2014, 2015). However, the pneumococcal PnpS HK lacks a recognizable PAS domain, and it remains to be determined whether PhoU2 regulation of $\mathrm{PnpR} \sim \mathrm{P}$ levels is through direct interactions with the PnpS HK. Likewise, it is unknown whether PhoU2 interacts with the PstB1 subunit of the Pst1 transporter to exert control over pst1phoU1 operon transcription, by analogy to control in E. coli (Gardner et al., 2014, 2015). Interactions of PhoU1 or PhoU2 with subunits of the Pst1 or Pst2 transporters also remain to be determined.

The requirement of a functional Pst1 or Pst2 for growth of the encapsulated serotype 2 strain provides a biological rationale for the constitutive expression and function of the Pst2 transporter at high $\mathrm{P}_{\mathrm{i}}$ concentrations (Table 2) and why $S$. pneumoniae maintains dual $\mathrm{P}_{\mathrm{i}}$ uptake systems. Capsule is one of the most important factors required for pneumococcal colonization, carriage, and virulence in its human host (Briles et al., 1992;
Morona et al., 2004, 2006; Bentley et al., 2006; Hyams et al., 2010). Expression of the Pst1 transporter is strongly induced by low $\mathrm{P}_{\mathrm{i}}$ conditions (Table 4), and lack of PhoU1 does not change pst1-phoU1 operon expression in high $\mathrm{P}_{\mathrm{i}}$ media (Tables 2, 4). These results, and a reduced rate of $\mathrm{P}_{\mathrm{i}}$ uptake by mutants lacking Pst1 (Figure 8C, Table S8) indicate that Pst1 functions mainly at low $\mathrm{P}_{\mathrm{i}}$ concentrations. However, encapsulated $S$. pneumoniae strains require high-affinity $P_{i}$ transport even in high- $P_{i}$ media (Table 2), and this $P_{i}$ uptake cannot be provided by the lowaffinity NptA Na ${ }^{+} / \mathrm{P}_{\mathrm{i}}$ cotransporter that replaces Pst1 and Pst2 in unencapsulated strains (Figure 8B, Table S7). The reason underlying this link between Pst-mediated $\mathrm{P}_{\mathrm{i}}$ transport and the maintenance of capsule is not currently clear. A recent report suggests that low $\mathrm{P}_{\mathrm{i}}$ conditions induce capsule biosynthesis in M. tuberculosis (van de Weerd et al., 2016). Overexpression of capsule could alter the metabolism of $S$. pneumoniae thereby inhibiting the growth of $c p s^{+} \Delta p s t 1 \Delta p s t 2$ mutants and leading to the appearance of spontaneous cps mutants (Table 2). However, starvation of the wild-type D39 $\mathrm{cps}^{+}$strain for $\mathrm{P}_{\mathrm{i}}$ for $1 \mathrm{~h}$ did not reveal a qualitative change in capsule amount in the Quellung reaction (data not shown). Moreover, pneumococcal capsule biosynthesis is positively regulated by phosphorylation of regulatory protein CpsD (Yother, 2011), and this protein phosphorylation would likely be reduced during $\mathrm{P}_{\mathrm{i}}$ limitation.

The regulatory pathways that mediate capsule induction in M. tuberculosis involve sigma factors and poly- $P_{i}$ kinases (van de Weerd et al., 2016) that are absent from S. pneumoniae. As mentioned in the Introduction, $\Delta p h o U$ mutants of other bacteria accumulate poly- $\mathrm{P}_{\mathrm{i}}$ (Morohoshi et al., 2002; Hirota et al., 2013; Wang et al., 2013; de Almeida et al., 2015; Lubin et al., 2016), possibly because high intracellular Pi concentration disrupt metabolic homeostasis leading to defects in growth accompanied by general antibiotic sensitivity. RNA-Seq results reported here indicate that the pneumococcal Pho regulon contains a limited number of recognizable genes involved in $\mathrm{P}_{\mathrm{i}}$ accumulation (Table S6). Notably, S. pneumoniae serotype 2 strain D39 as well as some other serotype strains, such as TIGR4, lack recognizable homologs of poly- $\mathrm{P}_{\mathrm{i}}$ kinases Ppk1 and Ppk2 (Zhang et al., 2002) and $\mathrm{Mg}^{2+}$-dependent poly- $\mathrm{P}_{\mathrm{i}}$ exopolyphosphatase $\mathrm{Ppx}$ (Akiyama et al., 1993), but do encode a degradative $\mathrm{Mn}^{2+}$. dependent, inorganic pyrophosphatase (PpaC) (Lanie et al., 2007); therefore, it is unclear whether these S. pneumoniae strains produces poly- $\mathrm{P}_{\mathrm{i}}$. DAPI staining experiments that revealed poly$\mathrm{P}_{\mathrm{i}}$ accumulation in C. crescentus $\Delta p h o U$ mutants (Lubin et al., 2016) were inconclusive and did not indicate any differences in staining of the phoU2 $2^{+}$parent and $\triangle$ phoU2 mutant in high$\mathrm{P}_{\mathrm{i}}$ BHI broth (data not shown). Similarly, DAPI-based assays of extracts did not show any difference between the parent and $\Delta$ phoU2 mutant indicative of different poly-Pi amounts (data not shown).

Taken together, our results suggest that $S$. pneumoniae may maintain the regulated Pst1 and constitutive Pst2 $\mathrm{P}_{\mathrm{i}}$ transport systems as a failsafe to ensure capsule biosynthesis is maintained during variations in $P_{i}$ conditions. Coordination between the two Pst $P_{i}$ transport systems is coordinated by the PhoU2 protein that modulates transcription of the pst1-phoU1 operon by the PnpRS TCS and separately regulates the function of 
A

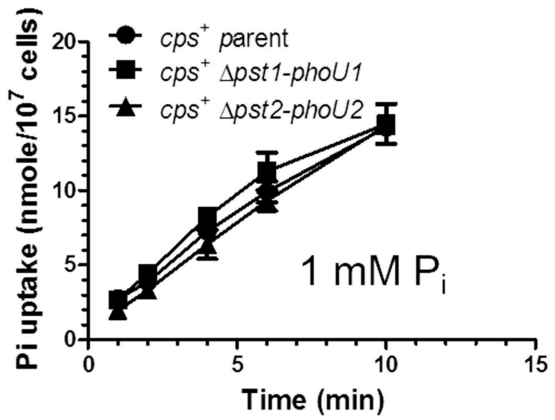

B

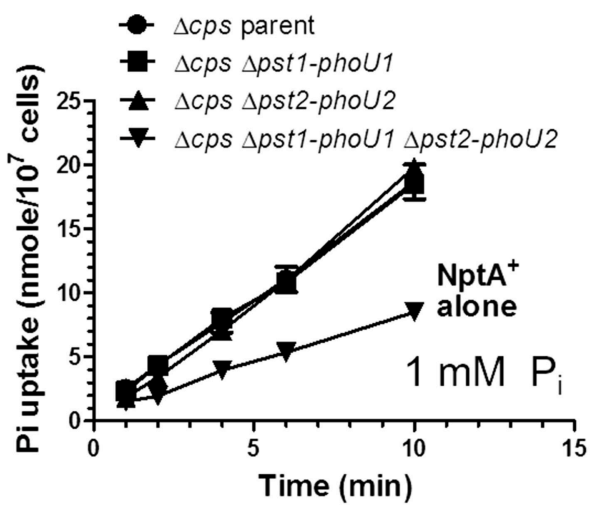

C

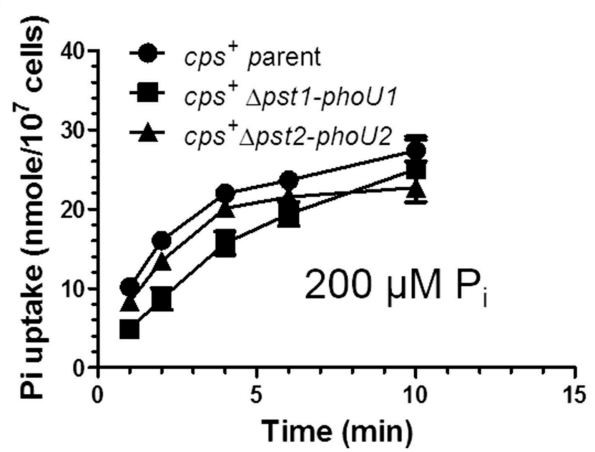

FIGURE 8 | The Pst1 or Pst2 transporter is sufficient for $P_{i}$ uptake under moderately high $P_{i}$ conditions (1 mM), but the Pst1 transporter is required for optimal $\mathbf{P}_{\mathbf{i}}$ uptake under low $\mathbf{P}_{\mathbf{i}}$ conditions $(200 \mu \mathbf{M})$ following $\mathbf{P}_{\mathbf{i}}$ limitation. (A) $P_{\mathbf{i}}$ uptake assays of encapsulated parent strain (IU1781) and $\Delta p s t 2-p h o U 2$ (IU6550) and $\Delta$ pst1-phoU1 (IU6830) mutants in $1 \mathrm{mM}$ total ${ }^{32} \mathrm{P}_{\mathrm{i}}$ in $\mathrm{mCDM}(n=3) . \mathrm{P}_{\mathrm{i}}$ uptake was determined as the initial rate of ${ }^{32} \mathrm{P}_{\mathrm{i}}$ incorporation into cells in mCDM in pulse-labeling experiments described in Materials and Methods. See Tables S7 for initial rates of $P_{i}$ uptake $(n=3)$. (B) $P_{i}$ uptake assays of unencapsulated parent strain $\Delta c p s$ (IU1945) and $\Delta c p s \Delta$ pst2-phoU2 (K583), $\Delta c p s \Delta$ pst1-phoU1 (E595), and $\Delta c p s \Delta$ pst1-phoU1 $\Delta$ pst2-phoU2 (IU5774) mutants in 1 mM Pi mCDM. See Tables S7 for initial rates of $\mathrm{P}_{\mathrm{i}}$ uptake $(n=3)$. (C) $\mathrm{P}_{\mathrm{i}}$ uptake assay of encapsulated parent strain (IU1781) and $\Delta$ pst2-phoU2 (IU6550) and $\Delta p s t 1-p h o U 1$ (IU6830) mutants in $200 \mu \mathrm{M}$ total $\mathrm{P}_{\mathrm{i}} \mathrm{mCDM}$ following $\mathrm{P}_{\mathrm{i}}$ starvation for $1 \mathrm{~h}$ as described in Materials and Methods $(n=3)$. Initial rates of Pi uptake were determined with the first min of labeling and are listed in Table S8 $(n=3)$.

the Pst2 transporter. Most bacteria encode a single Pst-type $P_{i}$ transporter as part of a Pho regulon that encode numerous phosphate accumulation and sparing proteins (Hulett, 1993; Wanner, 1996; Hsieh and Wanner, 2010). The limited Pho regulon of S. pneumoniae may reflect restriction to the human host, where $P_{i}$ is the primary source of phosphorus (Wilson, 2008). Even among the Streptococcus, dual Pst systems are limited to only a few species, including $S$. pneumoniae, $S$. pseudopneumoniae, S. dysgalactiae, S. equi (Group C), S. porcinus, S. agalactiae (Group B), and S. equinus, and are absent from the major Viridans and A Groups. Outside of the Streptococcus, multiple Pst $P_{i}$ transporters have only been reported in a very limited number of bacteria, including Synechocystis sp. PCC 6803 and M. tuberculosis (Braibant et al., 1996; Suzuki et al., 2004; Burut-Archanai et al., 2011; Tischler et al., 2013). In Synechocystis, low $\mathrm{P}_{\mathrm{i}}$ conditions activate expression of both of the Pst $\mathrm{P}_{\mathrm{i}}$ transporters that are present (Suzuki et al., 2004), whereas in M. tuberculosis one Pst transporter is activated by low $P_{i}$ and at least one other Pst transporter seems to be constitutively expressed, like Pst2 in S. pneumoniae (Tischler et al., 2013).

\section{AUTHOR CONTRIBUTIONS}

JZ, DS, KW, MW contributed to the conception and design of the work; JZ, DS carried out acquisition and analysis of data; JZ, DS, KW, MW interpreted data for the work; JZ, MW drafted and wrote the final version of the paper; JZ, DS, KW, MW approved the final version to be published.

\section{ACKNOWLEDGMENTS}

We thank Kevin Bruce, Tiffany Tsui, and other laboratory members for methods and critical discussions of this work, and James Ford, Kurt Zimmer, and Doug Rusch for assistance with Illumina DNA sequencing and RNA-Seq analyses. This work was supported by grants R21AI095814 and R01GM114315 (to MW).

\section{SUPPLEMENTARY MATERIAL}

The Supplementary Material for this article can be found online at: http://journal.frontiersin.org/article/10.3389/fcimb. 2016.00063 


\section{REFERENCES}

Akiyama, M., Crooke, E., and Kornberg, A. (1993). An exopolyphosphatase of Escherichia coli. J. Biol. Chem. 268:633-639.

Bansal, V. K. (1990). "Serum Inorganic Phosphorus," in Clinical Methods: The History, Physical, and Laboratory Examinations, eds H. K. Walker, W. D. Hall, and J. W. Hurst (Boston, MA: Butterworths Butterworth Publishers, a division of Reed Publishing), 895-899.

Beard, S. J., Hashim, R., Wu, G., Binet, M. R., Hughes, M. N., and Poole, R. K. (2000). Evidence for the transport of zinc(II) ions via the Pit inorganic phosphate transport system in Escherichia coli. FEMS Microbiol. Lett. 184, 231-235. doi: 10.1111/j.1574-6968.2000.tb09019.x

Benjamini, Y., and Hochberg, Y. (1995). Controlling the false discovery rate - a practical and powerful approach to multiple testing. J. Roy. Stat. Soc. B. Met. 57, 289-300.

Bentley, S. D., Aanensen, D. M., Mavroidi, A., Saunders, D., Rabbinowitsch, E., Collins, M., et al. (2006). Genetic analysis of the capsular biosynthetic locus from all 90 pneumococcal serotypes. PLoS Genet. 2:e31. doi: 10.1371/journal.pgen.0020031

Botella, E., Devine, S. K., Hubner, S., Salzberg, L. I., Gale, R. T., Brown, E. D., et al. (2014). PhoR autokinase activity is controlled by an intermediate in wall teichoic acid metabolism that is sensed by the intracellular PAS domain during the PhoPR-mediated phosphate limitation response of Bacillus subtilis. Mol. Microbiol. 94, 1242-1259. doi: 10.1111/mmi.12833

Botella, E., Hübner, S., Hokamp, K., Hansen, A., Bisicchia, P., Noone, D., et al. (2011). Cell envelope gene expression in phosphate-limited Bacillus subtilis cells. Microbiology 157, 2470-2484. doi: 10.1099/mic.0.049205-0

Braibant, M., Lefèvre, P., de Wit, L., Ooms, J., Peirs, P., Huygen, K., et al. (1996). Identification of a second Mycobacterium tuberculosis gene cluster encoding proteins of an ABC phosphate transporter. FEBS Lett. 394, 206-212. doi: 10.1016/0014-5793(96)00953-2

Briles, D. E., Crain, M. J., Gray, B. M., Forman, C., and Yother, J. (1992). Strong association between capsular type and virulence for mice among human isolates of Streptococcus pneumoniae. Infect. Immun. 60, 111-116.

Burut-Archanai, S., Eaton-Rye, J. J., and Incharoensakdi, A. (2011). $\mathrm{Na}^{+}$stimulated phosphate uptake system in Synechocystis sp. PCC 6803 with Pst1 as a main transporter. BMC Microbiol. 11:225. doi: 10.1186/1471-218011-225

Carvalho, S. M., Kuipers, O. P., and Neves, A. R. (2013). Environmental and nutritional factors that affect growth and metabolism of the pneumococcal serotype 2 strain D39 and its nonencapsulated derivative strain R6. PLoS ONE 8:e58492. doi: 10.1371/journal.pone.0058492

Chao, Y., Marks, L. R., Pettigrew, M. M., and Hakansson, A. P. (2014). Streptococcus pneumoniae biofilm formation and dispersion during colonization and disease. Front. Cell. Infect. Microbiol. 4:194. doi: 10.3389/fcimb.2014.00194

Chekabab, S. M., Harel, J., and Dozois, C. M. (2014a). Interplay between genetic regulation of phosphate homeostasis and bacterial virulence. Virulence 5, 786-793. doi: 10.4161/viru.29307

Chekabab, S. M., Jubelin, G., Dozois, C. M., and Harel, J. (2014b). PhoB activates Escherichia coli O157:H7 virulence factors in response to inorganic phosphate limitation. PLoS ONE 9:e94285. doi: 10.1371/journal.pone.0094285

Cheng, C., Wakefield, M. J., Yang, J., Tauschek, M., and Robins-Browne, R. M. (2012). Genome-wide analysis of the Pho regulon in a pstCA mutant of Citrobacter rodentium. PLoS ONE 7:e50682. doi: 10.1371/journal.pone.0050682

de Almeida, L. G., Ortiz, J. H., Schneider, R. P., and Spira, B. (2015). phoU inactivation in Pseudomonas aeruginosa enhances accumulation of ppGpp and polyphosphate. Appl. Environ. Microbiol. 81, 3006-3015. doi: 10.1128/AEM.04168-14

Donkor, E. S. (2013). Understanding the pneumococcus: transmission and evolution. Front. Cell. Infect. Microbiol. 3:7. doi: 10.3389/fcimb.2013.00007

Engel, H., Mika, M., Denapaite, D., Hakenbeck, R., Mühlemann, K., Heller, M., et al. (2014). A low-affinity penicillin-binding protein $2 \mathrm{x}$ variant is required for heteroresistance in Streptococcus pneumoniae. Antimicrob. Agents Chemother. 58, 3934-3941. doi: 10.1128/AAC.02547-14

Ferreira, D. M., and Gordon, S. B. (2015). "Mechanisms Causing the Inflammatory Response to Streptococcus pneumoniae," in Streptococcus pneumoniae Molecular Mechanisms of Host-Pathogen Interactions, eds J. M.
Brown, S. Hammerschmidt, and C. Orihuela (London: Academic Press), 383-400.

Gardner, S. G., Johns, K. D., Tanner, R., and McCleary, W. R. (2014). The PhoU protein from Escherichia coli interacts with PhoR, PstB, and metals to form a phosphate-signaling complex at the membrane. J. Bacteriol. 196, 1741-1752. doi: 10.1128/JB.00029-14

Gardner, S. G., Miller, J. B., Dean, T., Robinson, T., Erickson, M., Ridge, P. G., et al. (2015). Genetic analysis, structural modeling, and direct coupling analysis suggest a mechanism for phosphate signaling in Escherichia coli. BMC Genet. 16 (Suppl. 2):S2. doi: 10.1186/1471-2156-16-S2-S2

Gibson, J. L., Lombardo, M. J., Aponyi, I., Vera Cruz, D., Ray, M. P., and Rosenberg, S. M. (2015). Atypical role for PhoU in mutagenic break repair under stress in Escherichia coli. PLOS ONE 10:e0123315. doi: 10.1371/journal.pone.0123315

Glover, R. T., Kriakov, J., Garforth, S. J., Baughn, A. D., and Jacobs, W. R. Jr. (2007). The two-component regulatory system senX3-regX3 regulates phosphatedependent gene expression in Mycobacterium smegmatis. J. Bacteriol. 189, 5495-5503. doi: 10.1128/JB.00190-07

Gonin, M., Quardokus, E. M., O’Donnol, D., Maddock, J., and Brun, Y. V. (2000). Regulation of stalk elongation by phosphate in Caulobacter crescentus. J. Bacteriol. 182, 337-347. doi: 10.1128/JB.182.2.337-347.2000

Gratz, N., Loh, L. N., and Tuomanen, E. (2015). "Pneumococcal invasion: development of Bacteremia and Meningitis," in Streptococcus pneumoniae Molecular Mechanisms of Host-Pathogen Interactions, eds J. M. Brown, S. Hammerschmidt, and C. Orihuela (London: Academic Press), 433-451.

Grillo-Puertas, M., Rintoul, M. R., and Rapisarda, V. A. (2016). PhoB activation in non-limiting phosphate condition by the maintenance of high polyphosphate levels in stationary phase inhibits biofilm formation in Escherichia coli. Microbiology. doi: 10.1099/mic.0.000281. [Epub ahead of print].

Hakansson, A. P., Marks, L. R., and Roche-Hakansson, H. (2015). "Pneumococcal genetic transformation during colonization and biofilm formation," in Streptococcus pneumoniae Molecular Mechanisms of Host-Pathogen Interactions, eds J. M. Brown, S. Hammerschmidt, and C. Orihuela (London: Academic Press), 129-142.

Harris, R. M., Webb, D. C., Howitt, S. M., and Cox, G. B. (2001). Characterization of PitA and PitB from Escherichia coli. J. Bacteriol. 183, 5008-5014. doi: 10.1128/JB.183.17.5008-5014.2001

Hava, D. L., and Camilli, A. (2002). Large-scale identification of serotype 4 Streptococcus pneumoniae virulence factors. Mol. Microbiol. 45, 1389-1406. doi: 10.1046/j.1365-2958.2002.03106.x

Henriques-Normark, B., and Tuomanen, E. I. (2013). The pneumococcus: epidemiology, microbiology, and pathogenesis. Cold Spring Harb. Perspect. Med. 3:a010215. doi: 10.1101/cshperspect.a010215

Hirota, R., Motomura, K., Nakai, S., Handa, T., Ikeda, T., and Kuroda, A. (2013). Stable polyphosphate accumulation by a pseudo-revertant of an Escherichia coli phoU mutant. Biotechnol. Lett. 35, 695-701. doi: 10.1007/s10529-012-1133-y

Hoover, S. E., Perez, A. J., Tsui, H.-C. T., Sinha, D., Smiley, D. L., DiMarchi, R. D., et al. (2015). A new quorum sensing system (TprA/PhrA) for Streptococcus pneumoniae D39 that regulates a lantibiotic biosynthesis gene cluster. Mol. Microbiol. 97, 229-243. doi: 10.1111/mmi.13029

Howell, A., Dubrac, S., Noone, D., Varughese, K. I., and Devine, K. (2006). Interactions between the $\mathrm{YycFG}$ and PhoPR two-component systems in Bacillus subtilis: the PhoR kinase phosphorylates the non-cognate YycF response regulator upon phosphate limitation. Mol. Microbiol. 59, 1199-1215. doi: 10.1111/j.1365-2958.2005.05017.x

Hsieh, Y. J., and Wanner, B. L. (2010). Global regulation by the sevencomponent $\mathrm{P}_{\mathrm{i}}$ signaling system. Curr. Opin. Microbiol. 13, 198-203. doi: 10.1016/j.mib.2010.01.014

Hulett, F. M. (1993). "Regulation of phosphorus metabolism," in Bacillus Subtilis and Other Gram-Positive Bacteria Biochemistry, Physiology, and Molecular Genetics, eds A. L. Sonenshein, J. A. Hoch, and R. Losick (Washington, DC: ASM Press), 229-235.

Hyams, C., Camberlein, E., Cohen, J. M., Bax, K., and Brown, J. S. (2010). The Streptococcus pneumoniae capsule inhibits complement activity and neutrophil phagocytosis by multiple mechanisms. Infect. Immun. 78, 704-715. doi: 10.1128/IAI.00881-09

Jackson, R. J., Binet, M. R., Lee, L. J., Ma, R., Graham, A. I., McLeod, C. W., et al. (2008). Expression of the PitA phosphate/metal transporter of Escherichia coli 
is responsive to zinc and inorganic phosphate levels. FEMS Microbiol. Lett. 289, 219-224. doi: 10.1111/j.1574-6968.2008.01386.x

Jacobsen, S. M., Lane, M. C., Harro, J. M., Shirtliff, M. E., and Mobley, H. L. (2008). The high-affinity phosphate transporter Pst is a virulence factor for Proteus mirabilis during complicated urinary tract infection. FEMS Immunol. Med. Microbiol. 52, 180-193. doi: 10.1111/j.1574-695X.2007.00358.x

Katai, K., Miyamoto, K., Kishida, S., Segawa, H., Nii, T., Tanaka, H., et al. (1999). Regulation of intestinal $\mathrm{Na}^{+}$-dependent phosphate co-transporters by a lowphosphate diet and 1,25-dihydroxyvitamin D3. Biochem. J. 343, 705-712. doi: $10.1042 / \mathrm{bj} 3430705$

Katewa, S. D., and Katyare, S. S. (2003). A simplified method for inorganic phosphate determination and its application for phosphate analysis in enzyme assays. Anal. Biochem. 323, 180-187. doi: 10.1016/j.ab.2003.08.024

Kazmierczak, K. M., Wayne, K. J., Rechtsteiner, A., and Winkler, M. E. (2009). Roles of $\mathrm{rel}(\mathrm{Spn})$ in stringent response, global regulation and virulence of serotype 2 Streptococcus pneumoniae D39. Mol. Microbiol. 72, 590-611. doi: 10.1111/j.1365-2958.2009.06669.x

Lacks, S., and Hotchkiss, R. D. (1960). A study of the genetic material determining an enzyme in Pneumococcus. Biochim. Biophys. Acta 39, 508-518. doi: 10.1016/0006-3002(60)90205-5

Lamarche, M. G., Wanner, B. L., Crépin, S., and Harel, J. (2008). The phosphate regulon and bacterial virulence: a regulatory network connecting phosphate homeostasis and pathogenesis. FEMS Microbiol. Rev. 32, 461-473. doi: 10.1111/j.1574-6976.2008.00101.x

Lanie, J. A., Ng, W. L., Kazmierczak, K. M., Andrzejewski, T. M., Davidsen, T. M., Wayne, K. J., et al. (2007). Genome sequence of Avery's virulent serotype 2 strain D39 of Streptococcus pneumoniae and comparison with that of unencapsulated laboratory strain R6. J. Bacteriol. 189, 38-51. doi: 10.1128/JB.01148-06

Lebens, M., Lundquist, P., Söderlund, L., Todorovic, M., and Carlin, N. I. (2002). The nptA gene of Vibrio cholerae encodes a functional sodiumdependent phosphate cotransporter homologous to the type II cotransporters of eukaryotes. J. Bacteriol. 184, 4466-4474. doi: 10.1128/JB.184.16.44664474.2002

Lee, S. J., Park, Y. S., Kim, S. J., Lee, B. J., and Suh, S. W. (2014). Crystal structure of PhoU from Pseudomonas aeruginosa, a negative regulator of the Pho regulon. J. Struct. Biol. 188, 22-29. doi: 10.1016/j.jsb.2014.08.010

$\mathrm{Li}$, Y., and Zhang, Y. (2007). PhoU is a persistence switch involved in persister formation and tolerance to multiple antibiotics and stresses in Escherichia coli. Antimicrob. Agents Chemother. 51, 2092-2099. doi: 10.1128/AAC.00052-07

Liu, J., Lou, Y., Yokota, H., Adams, P. D., Kim, R., and Kim, S. H. (2005). Crystal structure of a PhoU protein homologue: a new class of metalloprotein containing multinuclear iron clusters. J. Biol. Chem. 280, 15960-15966. doi: 10.1074/jbc.M414117200

Lubin, E. A., Henry, J. T., Fiebig, A., Crosson, S., and Laub, M. T. (2016). Identification of the PhoB regulon and role of $\mathrm{PhoU}$ in the phosphate starvation response of Caulobacter crescentus. J. Bacteriol. 198, 187-200. doi: 10.1128/JB.00658-15

Martín, J. F. (2004). Phosphate control of the biosynthesis of antibiotics and other secondary metabolites is mediated by the PhoR-PhoP system: an unfinished story. J. Bacteriol. 186, 5197-5201. doi: 10.1128/JB.186.16.5197-5201.2004

McCluskey, J., Hinds, J., Husain, S., Witney, A., and Mitchell, T. J. (2004). A two-component system that controls the expression of pneumococcal surface antigen $\mathrm{A}(\mathrm{PsaA})$ and regulates virulence and resistance to oxidative stress in Streptococcus pneumoniae. Mol. Microbiol. 51, 1661-1675. doi: 10.1111/j.13652958.2003.03917.x

Moreno-Letelier, A., Olmedo, G., Eguiarte, L. E., Martinez-Castilla, L., and Souza, V. (2011). Parallel evolution and horizontal gene transfer of the pst operon in Firmicutes from oligotrophic environments. Int. J. Evol. Biol. 2011:781642. doi: $10.4061 / 2011 / 781642$

Morohoshi, T., Maruo, T., Shirai, Y., Kato, J., Ikeda, T., Takiguchi, N., et al. (2002). Accumulation of inorganic polyphosphate in phoU mutants of Escherichia coli and Synechocystis sp. strain PCC6803. Appl. Environ. Microbiol. 68, 4107-4110. doi: 10.1128/AEM.68.8.4107-4110.2002

Morona, J. K., Miller, D. C., Morona, R., and Paton, J. C. (2004). The effect that mutations in the conserved capsular polysaccharide biosynthesis genes $\operatorname{cps} A$, $c p s B$, and $c p s D$ have on virulence of Streptococcus pneumoniae. J. Infect. Dis. 189, 1905-1913. doi: $10.1086 / 383352$
Morona, J. K., Morona, R., and Paton, J. C. (2006). Attachment of capsular polysaccharide to the cell wall of Streptococcus pneumoniae type 2 is required for invasive disease. Proc. Natl. Acad. Sci. U.S.A. 103, 8505-8510. doi: 10.1073/pnas.0602148103

Muda, M., Rao, N. N., and Torriani, A. (1992). Role of PhoU in phosphate transport and alkaline phosphatase regulation. J. Bacteriol. 174, 8057-8064.

Neznansky, A., Blus-Kadosh, I., Yerushalmi, G., Banin, E., and Opatowsky, Y. (2014). The Pseudomonas aeruginosa phosphate transport protein PstS plays a phosphate-independent role in biofilm formation. FASEB J. 28, 5223-5233. doi: $10.1096 /$ fj.14-258293

Novak, R., Cauwels, A., Charpentier, E., and Tuomanen, E. (1999). Identification of a Streptococcus pneumoniae gene locus encoding proteins of an $\mathrm{ABC}$ phosphate transporter and a two-component regulatory system. J. Bacteriol. $181,1126-1133$.

Oganesyan, V., Oganesyan, N., Adams, P. D., Jancarik, J., Yokota, H. A., Kim, R., et al. (2005). Crystal structure of the "PhoU-like" phosphate uptake regulator from Aquifex aeolicus. J. Bacteriol. 187, 4238-4244. doi: 10.1128/JB.187.12.4238-4244.2005

Oliver, M. B., and Swords, W. E. (2015). "Pneumococcal biofilms and bacterial persistence during otitis media infections," in Streptococcus pneumoniae Molecular Mechanisms of Host-Pathogen Interactions, eds J. M. Brown, S. Hammerschmidt, and C. Orihuela (London: Academic Press), 293-308.

Orihuela, C. J., Mills, J., Robb, C. W., Wilson, C. J., Watson, D. A., and Niesel, D. W. (2001). Streptococcus pneumoniae PstS production is phosphate responsive and enhanced during growth in the murine peritoneal cavity. Infect. Immun. 69, 7565-7571. doi: 10.1128/IAI.69.12.7565-7571.2001

Paterson, G. K., Blue, C. E., and Mitchell, T. J. (2006). Role of two-component systems in the virulence of Streptococcus pneumoniae. J. Med. Microbiol. 55, 355-363. doi: 10.1099/jmm.0.46423-0

Polissi, A., Pontiggia, A., Feger, G., Altieri, M., Mottl, H., Ferrari, L., et al. (1998). Large-scale identification of virulence genes from Streptococcus pneumoniae. Infect. Immun. 66, 5620-5629.

Pratt, J. T., Ismail, A. M., and Camilli, A. (2010). PhoB regulates both environmental and virulence gene expression in Vibrio cholerae. Mol. Microbiol. 77, 1595-1605. doi: 10.1111/j.1365-2958.2010.07310.x

Qi, Y., Kobayashi, Y., and Hulett, F. M. (1997). The pst operon of Bacillus subtilis has a phosphate-regulated promoter and is involved in phosphate transport but not in regulation of the pho regulon. J. Bacteriol. 179, 2534-2539.

Ramos-Montañez, S., Tsui, H. C., Wayne, K. J., Morris, J. L., Peters, L. E., Zhang, F., et al. (2008). Polymorphism and regulation of the $s p x B$ (pyruvate oxidase) virulence factor gene by a CBS-HotDog domain protein (SpxR) in serotype 2 Streptococcus pneumoniae. Mol. Microbiol. 67, 729-746. doi: 10.1111/j.13652958.2007.06082.x

Rice, C. D., Pollard, J. E., Lewis, Z. T., and McCleary, W. R. (2009). Employment of a promoter-swapping technique shows that PhoU modulates the activity of the PstSCAB $2 \mathrm{ABC}$ transporter in Escherichia coli. Appl. Environ. Microbiol. 75, 573-582. doi: 10.1128/AEM.01046-08

Rifat, D., Bishai, W. R., and Karakousis, P. C. (2009). Phosphate depletion: a novel trigger for Mycobacterium tuberculosis persistence. J. Infect. Dis. 200, 1126-1135. doi: 10.1086/605700

Shah, M., Zaborin, A., Alverdy, J. C., Scott, K., and Zaborina, O. (2014). Localization of DING proteins on PstS-containing outer-surface appendages of Pseudomonas aeruginosa. FEMS Microbiol. Lett. 352, 54-61. doi: 10.1111/15746968.12368

Shi, W., and Zhang, Y. (2010). PhoY2 but not PhoY1 is the PhoU homologue involved in persisters in Mycobacterium tuberculosis. J. Antimicrob. Chemother. 65, 1237-1242. doi: 10.1093/jac/dkq103

Short, K. R., and Diavatopoulos, D. A. (2015). "Nasopharyngeal Colonization with Streptococcus pneumoniae," in Streptococcus pneumoniae Molecular Mechanisms of Host-Pathogen Interactions, eds. J. M. Brown, S. Hammerschmidt, and C. Orihuela (London: Academic Press), 279-291.

Soualhine, H., Brochu, V., Ménard, F., Papadopoulou, B., Weiss, K., Bergeron, M. G., et al. (2005). A proteomic analysis of penicillin resistance in Streptococcus pneumoniae reveals a novel role for PstS, a subunit of the phosphate ABC transporter. Mol. Microbiol. 58, 1430-1440. doi: 10.1111/j.13652958.2005.04914.x 
Staley, C., and Harwood, V. J. (2014). Differential expression of a sodiumphosphate cotransporter among Vibrio vulnificus strains. Microb. Ecol. 67, 24-33. doi: 10.1007/s00248-013-0300-6

Steed, P. M., and Wanner, B. L. (1993). Use of the rep technique for allele replacement to construct mutants with deletions of the pstSCAB-phoU operon: evidence of a new role for the PhoU protein in the phosphate regulon. J. Bacteriol. 175, 6797-6809.

Sung, C. K., Li, H., Claverys, J. P., and Morrison, D. A. (2001). An $r p s L$ cassette, janus, for gene replacement through negative selection in Streptococcus pneumoniae. Appl. Environ. Microbiol. 67, 5190-5196. doi: 10.1128/AEM.67.11.5190-5196.2001

Suzuki, S., Ferjani, A., Suzuki, I., and Murata, N. (2004). The SphS-SphR two component system is the exclusive sensor for the induction of gene expression in response to phosphate limitation in synechocystis. J. Biol. Chem. 279, 13234-13240. doi: 10.1074/jbc.M313358200

Takemaru, K., Mizuno, M., and Kobayashi, Y. (1996). A Bacillus subtilis gene cluster similar to the Escherichia coli phosphate-specific transport ( $p s t$ ) operon: evidence for a tandemly arranged pstB gene. Microbiology 142, 2017-2020. doi: 10.1099/13500872-142-8-2017

Throup, J. P., Koretke, K. K., Bryant, A. P., Ingraham, K. A., Chalker, A. F., Ge, Y., et al. (2000). A genomic analysis of two-component signal transduction in Streptococcus pneumoniae. Mol. Microbiol. 35, 566-576. doi: 10.1046/j.13652958.2000.01725.x

Tiraby, J. G., and Fox, M. S. (1973). Marker discrimination in transformation and mutation of pneumococcus. Proc. Natl. Acad. Sci. U.S.A. 70, 3541-3545. doi: 10.1073/pnas.70.12.3541

Tischler, A. D., Leistikow, R. L., Kirksey, M. A., Voskuil, M. I., and McKinney, J. D. (2013). Mycobacterium tuberculosis requires phosphate-responsive gene regulation to resist host immunity. Infect. Immun. 81, 317-328. doi: 10.1128/IAI.01136-12

Trihn, M., Ge, X., Dobson, A., Kitten, T., Munro, C. L., and Xu, P. (2013). Twocomponent system response regulators involved in virulence of Streptococcus pneumoniae TIGR4 in infective endocarditis. PLoS ONE 8:e54320. doi: 10.1371/journal.pone. 0054320

Tsui, H. C., Boersma, M. J., Vella, S. A., Kocaoglu, O., Kuru, E., Peceny, J. K., et al. (2014). Pbp2x localizes separately from Pbp2b and other peptidoglycan synthesis proteins during later stages of cell division of Streptococcus pneumoniae D39. Mol. Microbiol. 94, 21-40. doi: 10.1111/mmi.12745

Tsui, H. C., Mukherjee, D., Ray, V. A., Sham, L. T., Feig, A. L., and Winkler, M. E. (2010). Identification and characterization of noncoding small RNAs in Streptococcus pneumoniae serotype 2 strain D39. J. Bacteriol. 192, 264-279. doi: 10.1128/JB.01204-09

Tsui, H. T., Zheng, J. J., Magallon, A. N., Ryan, J. D., Yunck, R., Rued, B. E., et al. (2016). Suppression of a deletion mutation in the gene encoding essential PBP2b reveals a new lytic transglycosylase involved in peripheral peptidoglycan synthesis in Streptococcus pneumoniae D39. Mol. Microbiol. 100, 1039-1065. doi: $10.1111 / \mathrm{mmi} .13366$

van de Weerd, R., Boot, M., Maaskant, J., Sparrius, M., Verboom, T., van Leeuwen, L. M., et al. (2016). Inorganic phosphate limitation modulates capsular polysaccharide composition in Mycobacteria. J. Biol. Chem. 291, 11787-11799. doi: 10.1074/jbc.M116.722454 van Opijnen, T., and Camilli, A. (2012). A fine scale phenotype-genotype virulence map of a bacterial pathogen. Genome Res. 22, 2541-2551. doi: 10.1101/gr.137430.112

van Veen, H. W., Abee, T., Kortstee, G. J., Konings, W. N., and Zehnder, A. J. (1994). Translocation of metal phosphate via the phosphate inorganic transport system of Escherichia coli. Biochemistry 33, 1766-1770. doi: 10.1021/bi00173a020

Vernatter, J., and Pirofski, L. A. (2013). Current concepts in host-microbe interaction leading to pneumococcal pneumonia. Curr. Opin. Infect. Dis. 26, 277-283. doi: 10.1097/QCO.0b013e3283608419

Wang, C., Mao, Y., Yu, J., Zhu, L., Li, M., Wang, D., et al. (2013). PhoY2 of Mycobacteria is required for metabolic homeostasis and stress response. J. Bacteriol. 195, 243-252. doi: 10.1128/JB.01556-12

Wanner, B. L. (1996). "Phosphorus assimilation and control of the phosphate regulon," in Escherichia coli and Salmonella typhimurium cellular and molecular biology, Vol. 2, eds F. C. Neidhardt, R. III. Curtis, J. L. Ingraham, E. C. C. Lin, K. B. Low, B. Magasanik, W. S. Reznikoff, M. Riley, M. Schaechter, and H. E. Umbarger (Washington, DC: ASM Press), 1357-1381.

Wayne, K. J., Li, S., Kazmierczak, K. M., Tsui, H. C., and Winkler, M. E. (2012). Involvement of WalK (VicK) phosphatase activity in setting WalR (VicR) response regulator phosphorylation level and limiting cross-talk in Streptococcus pneumoniae D39 cells. Mol. Microbiol. 86, 645-660. doi: 10.1111/mmi.12006

Wayne, K. J., Sham, L. T., Tsui, H. C., Gutu, A. D., Barendt, S. M., Keen, S. K., et al. (2010). Localization and cellular amounts of the WalRKJ (VicRKX) twocomponent regulatory system proteins in serotype 2 Streptococcus pneumoniae. J. Bacteriol. 192, 4388-4394. doi: 10.1128/JB.00578-10

Wilson, M. (2005). Microbial Inhabitants of Humans: Their Ecology and Role in Health and Disease. Cambridge: Cambridge University Press.

Wilson, M. (2008). Bacteriology of Humans an Ecological Perspective. Malen, MA: Blackwell Publishing.

Yother, J. (2011). Capsules of Streptococcus pneumoniae and other bacteria: paradigms for polysaccharide biosynthesis and regulation. Annu. Rev. Microbiol. 65, 563-581. doi: 10.1146/annurev.micro.62.081307.162944

Zaborina, O., Holbrook, C., Chen, Y., Long, J., Zaborin, A., Morozova, I., et al. (2008). Structure-function aspects of PstS in multi-drug-resistant Pseudomonas aeruginosa. PLoS Pathog. 4:e43. doi: 10.1371/journal.ppat.0040043

Zhang, H., Ishige, K., and Kornberg, A. (2002). A polyphosphate kinase (PPK2) widely conserved in bacteria. Proc. Natl. Acad. Sci. U.S.A. 99, 16678-16683. doi: 10.1073/pnas.262655199

Conflict of Interest Statement: The authors declare that the research was conducted in the absence of any commercial or financial relationships that could be construed as a potential conflict of interest.

Copyright (c) 2016 Zheng, Sinha, Wayne and Winkler. This is an open-access article distributed under the terms of the Creative Commons Attribution License (CC BY). The use, distribution or reproduction in other forums is permitted, provided the original author(s) or licensor are credited and that the original publication in this journal is cited, in accordance with accepted academic practice. No use, distribution or reproduction is permitted which does not comply with these terms. 